OPEN ACCESS

Edited by:

Mark P. Burns,

Georgetown University, United States

Reviewed by:

Peng Lei,

State Key Laboratory of Biotherapy

(SKLB), China

Rafael Linden,

Universidade Federal do Rio de Janeiro, Brazil

*Correspondence: Jan Lewerenz jan.lewerenz@uni-ulm.de Pamela Maher pmaher@salk.edu

Specialty section: This article was submitted to Neurodegeneration,

a section of the journal Frontiers in Neuroscience

Received: 19 January 2018 Accepted: 19 March 2018 Published: 20 April 2018

Citation:

Lewerenz J, Ates G, Methner A,

Conrad $M$ and Maher $P$ (2018) Oxytosis/Ferroptosis - (Re-) Emerging Roles for Oxidative Stress-Dependent Non-apoptotic Cell Death in Diseases of the Central Nervous System.

Front. Neurosci. 12:214. doi: 10.3389/fnins.2018.00214

\section{Oxytosis/Ferroptosis-(Re-) Emerging Roles for Oxidative Stress-Dependent Non-apoptotic Cell Death in Diseases of the Central Nervous System}

\author{
Jan Lewerenz ${ }^{1 *}$, Gamze Ates ${ }^{2}$, Axel Methner ${ }^{3}$, Marcus Conrad ${ }^{4}$ and Pamela Maher ${ }^{2 *}$ \\ ${ }^{1}$ Department of Neurology, Ulm University, Ulm, Germany, ${ }^{2}$ Cellular Neurobiology Laboratory, The Salk Institute for Biological \\ Studies, La Jolla, CA, United States, ${ }^{3}$ Department of Neurology, University Medical Center and Focus Program Translational \\ Neuroscience of the Johannes Gutenberg-University Mainz, Mainz, Germany, ${ }^{4}$ Institute of Developmental Genetics, \\ Helmholtz Zentrum München, Neuherberg, Germany
}

Although nerve cell death is the hallmark of many neurological diseases, the processes underlying this death are still poorly defined. However, there is a general consensus that neuronal cell death predominantly proceeds by regulated processes. Almost 30 years ago, a cell death pathway eventually named oxytosis was described in neuronal cells that involved glutathione depletion, reactive oxygen species production, lipoxygenase activation, and calcium influx. More recently, a cell death pathway that involved many of the same steps was described in tumor cells and termed ferroptosis due to a dependence on iron. Since then there has been a great deal of discussion in the literature about whether these are two distinct pathways or cell type- and insult-dependent variations on the same pathway. In this review, we compare and contrast in detail the commonalities and distinctions between the two pathways concluding that the molecular pathways involved in the regulation of ferroptosis and oxytosis are highly similar if not identical. Thus, we suggest that oxytosis and ferroptosis should be regarded as two names for the same cell death pathway. In addition, we describe the potential physiological relevance of oxytosis/ferroptosis in multiple neurological diseases.

Keywords: programmed cell death, oxytosis, ferroptosis, iron, oxidative stress, brain diseases

\section{INTRODUCTION}

Among all of the tissues in the body, the human brain is unique with regard to its complexity. About 86 billion neurons (Herculano-Houzel, 2009) are interconnected to enable an incredible array of responses to exterior stimuli that manifest either as behaviors or as processes that we experience as emotions, thoughts or memories. In addition, the brain is also unique with respect to the longevity of the neuronal cells, which for the most part are as old as the individual (Bhardwaj et al., 2006). With life expectancy increasing worldwide (Robine and Cubaynes, 2017), it is not surprising that diseases characterized by dysfunction of the central nervous system (CNS) like Alzheimer's (AD) and Parkinson's disease (PD) are expected to sharply rise in aging societies. In addition, other neurodegenerative diseases like amyotrophic lateral sclerosis (ALS) or Huntington's disease (HD) 
pose a tremendous burden both on the patients and the families and caregivers (Domaradzki, 2015; Oh et al., 2015; de Wit et al., 2017). Of note, there are no treatments that stop or reverse any of the aforementioned diseases. Although the pathophysiology of these diseases may vary greatly and the neurons affected show characteristic neuroanatomical distributions, the neurological symptoms caused by the functional impairment are the result of either neuronal dysfunction or death (Herms and Dorostkar, 2016; Handley et al., 2017; Jackson et al., 2017). Neuronal dysfunction, at least experimentally, is reversible (Verity and Mallucci, 2011). However, when neuronal death exceeds a certain threshold, it cannot be functionally compensated for in most areas of the brain (Clement and Belleville, 2010; Malejko et al., 2014). In humans, neurogenesis is thought to occur only in the hippocampus and to a lesser degree in the striatum throughout the lifespan (Bergmann et al., 2015). However, even this has been questioned recently (Sorrells et al., 2018). Consequently, a better understanding of how neurons actually die during neurodegenerative diseases could pave the way for treatments whose ultimate goal is not just to rescue neurons from death but also to re-establish proper neuronal function in these rescued neuronal populations.

In stark contrast to its relevance, there is surprisingly little knowledge about the exact mechanism(s) that underlie neuronal death in different diseases of the brain. Within the last two decades, the dichotomy between apoptosis (previously meaning programmed cell death), and necrosis (referring to an accidental, unregulated cell death) has proven to be an oversimplification as a myriad of regulated cell death subroutines distinct from apoptosis have been described. These include necroptosis (Degterev et al., 2005), parthanatos (Andrabi et al., 2006), oxytosis (Tan et al., 2001a), and ferroptosis (Dixon et al., 2012), to name a few. Yet, the caveat of this new perception is that many of the reports mostly rely on in vitro observations. It has proven to be extremely difficult to unequivocally assign which of these different pathways is responsible for neuronal loss in various disease states in vivo. The main hurdle to achieving a better understanding of neuronal death processes in different diseases is that neurodegeneration is a very slow process leaving it very challenging to pinpoint neurons that are in the actual process of succumbing to cell death in either autoptic tissues or brains of animal models of CNS diseases. In addition, with the exception of apoptosis (Kerr et al., 1972) and necroptosis (Sun et al., 2012), no established morphological or biochemical markers are available for these different types of cell death. In this review, we describe the historical aspects of the discovery of two highly related, if not identical, forms of regulated cell death, oxytosis and ferroptosis, and summarize the current state of knowledge with respect to their relevance for neuronal death in diseases of the CNS.

\section{REGULATED CELL DEATH-APOPTOSIS AND BEYOND}

Apoptosis, the first described form of regulated cell death, has long been used as a synonym for all forms of regulated cell death including programmed cell death during development. Morphologically, apoptosis is characterized by membrane blebbing, nuclear condensation and fragmentation and cell shrinkage (Kerr et al., 1972). Initiated either by the intrinsic pathway, which includes mitochondrial cytochrome $\mathrm{C}$ release and subsequent activation of caspase 9 (reviewed by Fuchs and Steller, 2011) or by extrinsic stimuli, which involves the activation of death receptors by their cognate ligands, tumor necrosis factor $\alpha(\mathrm{TNF} \alpha)$, TRAIL, and FasL, and subsequent activation of caspase 8 (reviewed by Christofferson and Yuan, 2010), apoptosis is executed by the downstream activation of caspases 3 and 7. These, in turn, cleave several hundred different cellular target proteins (reviewed by Luthi and Martin, 2007), resulting in the typical morphological changes and biochemical hallmarks of apoptosis, e.g., 200 bp internucleosomal DNA fragmentation by the caspase-activated DNase (CAD)/DFF40 nuclease (Wyllie, 1980; Liu et al., 1997). In addition, the Kroemer laboratory purified a protein called apoptosis-inducing factor (AIF) that in a caspase-independent manner induces apoptosisspecific structural nuclear changes associated with large scale DNA fragmentation rather than internucleosomal DNA cleavage (Susin et al., 1999).

Almost 30 years ago, Laster and colleagues were the first to observe that $\mathrm{TNF} \alpha$-induced cell death in some sensitive cell lines and under certain conditions is distinct from apoptosis (Laster et al., 1988). This type of cell death was later termed necroptosis (Degterev et al., 2005). It was repeatedly shown that cells undergo this type of regulated cell death when apoptosis is pharmacologically/genetically impeded (Vercammen et al., 1998a,b; Holler et al., 2000; Conrad et al., 2016). Necroptosis requires the kinase activity of receptor-interacting protein 1 (RIP1; also known as RIPK1) and RIP3 (also known as RIPK3), which - among others are the central components of a multi-protein complex called the necrosome (Vanden Berghe et al., 2016). Downstream of necrosome formation, RIPK3-mediated mixed lineage kinase domain-like protein (MLKL) phosphorylation (Wang et al., 2014), translocation and association of phosphorylated MLKL with phosphatidylinositol phosphates in the plasma membrane, pore formation and influx of calcium ions have been reported to be critical events in the execution of necroptosis (Dondelinger et al., 2014; Wang et al., 2014).

Alternatively, activation of poly(ADP-ribose) polymerase 1 (PARP1) may lead to another distinct, non-apoptotic cell death paradigm called parthanatos (Andrabi et al., 2006; Jouan-Lanhouet et al., 2012). It has been hypothesized that poly-(ADP-ribosyl)-polymers (PARs) generated by abnormal PARP1 activity either modify nuclear proteins or act as signaling molecules to modify proteins in other compartments such as AIF in the mitochondria or hexokinase in the cytosol (Smulson et al., 2000; Andrabi et al., 2014). Experimentally, parthanatos was reported to be triggered in response to the alkylating agent $\mathrm{N}$-methyl- $\mathrm{N}^{\prime}$-nitro- $\mathrm{N}$ nitrosoguanidine in fibroblasts as well as UV light, ionizing radiation and during excitotoxic cell death in neurons (Yu et al., 2002). 


\section{OXYTOSIS-REGULATED CELL DEATH INDUCED BY GLUTATHIONE DEPLETION}

In the same year when non-apoptotic regulated cell death was observed in response to TNF $\alpha$ (Laster et al., 1988), Murphy and colleagues from Coyle's group reported that in the N18-RE105 neuroblastoma $\mathrm{X}$ retina cell line, glutamate as well as the glutamate analogs quisqualate and ibotenate induced a calciumdependent form of delayed cell death (Murphy et al., 1988). This type of cell death was associated with depletion of intracellular glutathione (GSH) as it was exacerbated by low cystine medium (a GSH precursor), characterized by increased oxidative stress and inhibited by lipophilic antioxidants (Miyamoto et al., 1989). It was also observed in immature hippocampal neurons (Murphy et al., 1990). The mechanistic link between glutamate exposure and GSH depletion proved to be glutamate-mediated inhibition of cystine import (Murphy et al., 1989). Already at this point, it became apparent that the transport system responsible for glutamate-inhibitable cystine uptake shared similarities with system $\mathrm{x}_{c}^{-}$, a cystine glutamate antiporter originally characterized by Bannai and Kitamura (1980). Although a similar type of cell death was also reported in rat PC12 pheochromocytoma cells (Schubert et al., 1992), most of the subsequent studies addressing this type of glutamate toxicity-initially called oxidative glutamate toxicity-were carried out in HT22 cells, a subclone of the hippocampal cell line HT4 (Morimoto and Koshland, 1991) that was specifically selected for its sensitivity to glutamate (Davis and Maher, 1994). Using this cell-based model, it was possible to characterize in detail the biochemical events that sequentially lead to cell death. It was demonstrated that this type of cell death is associated with a prominent increase in reactive oxygen species (ROS) generation following GSH depletion, which is followed by the final lethal influx of calcium (Tan et al., 2001a). In 2001, oxytosis-a term that highlights both the ROS accumulation that is characteristic of this type of cell death as well as the fact that it is a form of regulated cell death distinct from apoptosis-was coined for this new form of non-apoptotic regulated cell death (Tan et al., 2001a).

\section{FERROPTOSIS-AN IRON-DEPENDENT NON-APOPTOTIC FORM OF REGULATED CELL DEATH INDUCED BY POTENTIAL ANTI-CANCER DRUGS}

Using a high through-put screen for new genotype-specific anticancer therapeutics, Stockwell's group identified in 2003 a novel compound, erastin, which induced non-apoptotic cell death in human transformed foreskin fibroblasts (Dolma et al., 2003). This type of cell death proved to be associated with the loss of mitochondrial integrity and mitochondrial ROS generation in the absence of morphological or biochemical features of apoptosis (Yagoda et al., 2007). Erastin-induced cell death could be blocked by lipophilic antioxidants (Yagoda et al., 2007). Later, the compound RSL3 was identified that induced a similar type of cell death (Yang and Stockwell, 2008). As it could be demonstrated that cells genetically sensitized to this type of cell death show higher levels of intracellular iron (Yang and Stockwell, 2008), and that cell death could be inhibited by structurally different iron chelators, it was named ferroptosis (Yang and Stockwell, 2008; Dixon et al., 2012).

\section{ARE FERROPTOSIS AND OXYTOSIS JUST TWO NAMES FOR THE SAME FORM OF REGULATED NON-APOPTOTIC CELL DEATH?}

The key initiating step in most experimental paradigms for oxytosis is the inhibition of cystine uptake into the cells. Cystine can be imported into cells via four transport systems: excitatory amino acid transporters (EAATs) (Hayes et al., 2005), system $\mathrm{b}^{0,+}$, a heterodimer of rBAT with SLC7A9 (Chillaron et al., 2010), a heterodimer of rBAT with AGT1/SLC7A13 that mediates the counter transport of aspartate, glutamate and cystine (Nagamori et al., 2016) and system $\mathrm{x}_{c}^{-}$(Lewerenz et al., 2013). System $x_{c}^{-}$is a heterodimeric amino acid transporter comprising $\mathrm{xCT}$ (SLC7A11) and 4F2hc (SLC3A2) as the heavy chain, which specifically transports cystine, glutamate, and the non-proteinogenic amino acid cystathionine (Lewerenz et al., 2013; Kobayashi et al., 2015). The fact that system $x_{c}^{-}$ inhibition pharmacologically through substrate inhibitors like aminoadipate, homocysteate, and quisqualate (Murphy et al., 1989, 1990; Maher and Davis, 1996) or genetically in cells derived from xCT knock-out mice (Sato et al., 2005) induces cell death indicates that system $x_{c}^{-}$inhibition is responsible for the initiation of oxytosis by inhibiting cystine uptake in most cells studied. However, in addition to cystine starvation or inhibition of cystine import, inhibition of GSH synthesis by buthionine sulfoximine (BSO), an inhibitor of glutamate cysteine ligase (GCL), the rate-limiting enzyme in GSH biosynthesis, can induce oxytosis (Li et al., 1998; Ishige et al., 2001b; Lewerenz et al., 2003). This indicates the relevance of GSH depletion for the initiation of oxytosis in cells sensitive to this type of cell death whereas in the presence of high expression of $\mathrm{xCT}$, cystine/cysteine might compensate for the GSH deficiency (Banjac et al., 2008; Mandal et al., 2010).

Most interestingly, the first reported inducer of ferroptosis, erastin (Dixon et al., 2012) is a system $\mathrm{x}_{\mathrm{c}}^{-}$inhibitor (Dixon et al., 2014) and transcriptome changes induced by erastin can be reverted by by-passing cysteine depletion due to system $\mathrm{x}_{\mathrm{c}}^{-}$ inhibition by using $\beta$-ME in the culture medium (Dixon et al., 2014) similar to XCT KO mice (Sato et al., 2005). Hence, it is reasonable to assume that oxytosis and ferroptosis represent very similar (or even the same) forms of regulated cell death. Therefore, in the following sections we will summarize the similarities and differences and discrepancies for non-apopotic regulated cell death termed either oxytosis or ferroptosis.

\section{THE ROLE OF LIPOXYGENASES IN THE EXECUTION OF FERROPTOSIS AND OXYTOSIS}

The series of events leading to cell death by oxytosis following the inhibition of system $\mathrm{x}_{\mathrm{c}}^{-}$or cystine starvation have 
been quite well-characterized, although some questions and controversies remain. First, GSH levels drop in a time-dependent manner while ROS, as measured by dichlorofluorescein (DCF) fluorescence (a probe that mostly detects hydrophilic ROS; Li and Pratt, 2015), exhibit a linear increase (Tan et al., 1998a). However, when GSH falls below 20\% (6-8 h of glutamate treatment), an exponential increase in ROS levels ensues (Tan et al., 1998a). Subsequent experiments identified 12-lipoxygenase activity (12-LOX) and 12-LOXmediated peroxidation of arachidonic acid as an important link between GSH depletion and ROS accumulation (Li et al., 1997b). During the induction of oxytosis, the cellular uptake of arachidonic acid is enhanced, 12-LOX activity (measured as the production of ${ }^{3} \mathrm{H}$-12-hydroxyeicosatetraenoic acid (HETE) from ${ }^{3} \mathrm{H}$-arachidonic acid in cell lysates) was increased and LOX proteins were translocated to the plasma membrane. In addition, exogenous arachidonic acid potentiates oxytotic cell death. Currently, the precise LOX responsible for the 12-LOX activity is not clear. HT22 cells do not express ALOX15, ALOX12, or ALOX12b, but only ALOX15B (our unpublished observations and Wenzel et al., 2017). Moreover, murine ALOX15B exhibits almost exclusively 8LOX activity (Jisaka et al., 1997). Inhibition of LOX activity in HT22 cells by multiple inhibitors with different reported specificities including NDGA, baicalein, CDC, AA-861 and 5,8,11,14-ETYA blocked ROS accumulation and cell death induced by GSH depletion (Li et al., 1997b; Pallast et al., 2009). Interestingly, murine embryonic fibroblasts (MEF) deficient in ALOX15 were protected against BSO-induced cell death (Seiler et al., 2008). Surprisingly, the ALOX5 inhibitor zileuton (Carter et al., 1991) also protected HT22 cells against glutamate-induced oxytosis and ferroptosis induced by erastin (Liu et al., 2015).

A highly similar pharmacological profile was reported for genetically-engineered MEF in which cell death associated with massive lipid peroxidation could be induced via glutathione peroxidase 4 (GPX4) inactivation (Seiler et al., 2008). Here, both linoleic and arachidonic acid exacerbated cell death, while multiple LOX inhibitors (NDGA, AA861, baicalein, PD146176, MK866, MJ33, BWA4C, and zileuton) protected against GPX4 deficiency (Seiler et al., 2008; Friedmann Angeli et al., 2014). A similar array of LOX inhibitors protected against ferroptosis induced by RSL3 in acute lymphatic leukemia cells (Probst et al., 2017). MEFs express ALOX15, ALOX12, ALOX12B, and ALOX5, but not ALOX15B. Whereas ALOX15 deficiency alone did not rescue cell death induced by GPX4 inactivation in MEFs, additional knock-down of ALOX5 did delay cell death (Friedmann Angeli et al., 2014). The human fibrosarcoma cell line HT1080 expresses ALOX15, ALOX12, ALOX12B, ALOX5, ALOX15B, and ALOXE3 (Yang et al., 2016). In these cells, knock-down of both ALOX15B and ALOXE3 was sufficient to recapitulate the protective effect of pharmacological LOX inhibition against erastin-induced cell death (Yang et al., 2016). In G-401 rhabdoid tumor cells, which express all LOX isoforms, knock-down of all of these protected against ferroptosis induced by system $\mathrm{x}_{\mathrm{c}}^{-}$ inhibition, but not against RSL3-induced ferroptosis (Yang et al.,
2016). Moreover, when deuterated linoleate was incorporated into the membranes of these cells, they became resistant to ferroptosis (Yang et al., 2016). Deuterated polyunsaturated fatty acids have deuterium in place of the bis-allylic hydrogens, which slows the initiation of deuterium abstraction and subsequent radical generation (Shchepinov et al., 2011). In addition, a p53-induced increase in spermidine/spermine N1acetyltransferase sensitizes cells to tert-butylhydroperoxideinduced ferroptosis via transcriptional induction of ALOX15 (Ou et al., 2016). Using redox phospholipidomics, Kagan et al. showed that double- and triple-oxygenated arachidonic and adrenic acid-containing phosphatidylethanolamine species with $\mathrm{C} 18$ fatty acids (C18:0 or C18:1) at the sn-1 position and $\mathrm{C} 20: 4$ or $\mathrm{C} 22: 4$ fatty acids at the sn-2 position are the preferential substrates for LOX in ferroptosis induced by RSL3 or GPX4 deficiency in MEF (Kagan et al., 2017). Similar oxygenated lipid species were found to be generated in cell lysates by human recombinant ALOX15. Moreover, it was proposed that vitamin E species as well as the ferroptosis inhibitors liproxstatin-1 and ferrostatin-1 inhibit LOX (Wenzel et al., 2017; Zilka et al., 2017). However, as both liproxstatin-1 and ferrostatin-1 inhibit ferroptosis at concentrations not high enough to inhibit human ALOX15 overexpressed in HEK cells, it was concluded that their ability to protect against ferroptosis is independent of LOX inhibition.

The activity of acetyl-CoA synthetase long-chain member 4 (ACSL4) was shown to be essential for cells undergoing ferroptosis (Doll et al., 2017). ACLS4 knock-out cells accumulate only free oxidized polyunsaturated fatty acids (PUFAs), indicating that esterified oxidized PUFAs contribute to the generation of proximate signals of ferroptosis (Kagan et al., 2017). Recently, it was proposed that when ALOX15 or ALOX15B form complexes with the promiscuous small scaffolding protein phosphatidylethanolamine-binding protein 1 (PEBP1), their ability to oxidize PUFAs shifts from free PUFAs to esterified PUFAs thereby inducing the generation of phosphatidiylethanolamine lipid hydroperoxides (Wenzel et al., 2017). Most interestingly, ALOX15 has been reported to be involved in programmed organelle degradation by binding to intracellular membranes of various organelles while sparing the plasma membrane (van Leyen et al., 1998) and ALOX15 was further shown to bind to mitochondria in vitro causing membrane disintegration and ROS generation (Pallast et al., 2009). This is consistent with the disintegration of intracellular organelles observed in oxytosis (Tan et al., 1998b; Tirosh et al., 2000) and ferroptosis (Dixon et al., 2012; Friedmann Angeli et al., 2014; Doll et al., 2017) (Figure 1).

In summary, most of these results indicate that oxytosis and ferroptosis rely on LOX activity for the initiation of maximal ROS production, which ultimately leads to cell death. Although the specific LOX(s) involved likely depend on the cell type, the current data support a model where GSH depletion leads to the activation of LOX, which then interacts with PEBP1 and binds to membranes, especially of intracellular organelles, where the cell death propagating lipid-ROS, oxidized 


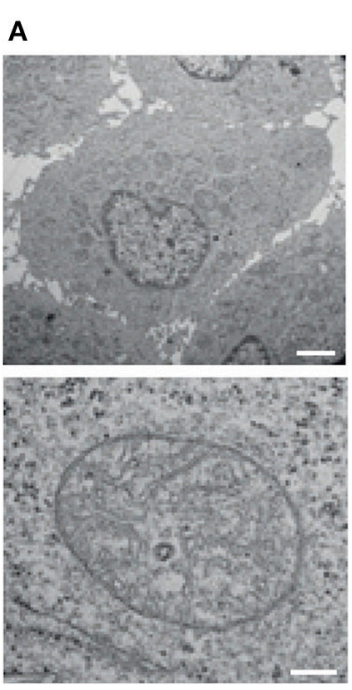

$0 \mathrm{~min}$

\section{Mouse embryonic fibroblasts + RSL3}
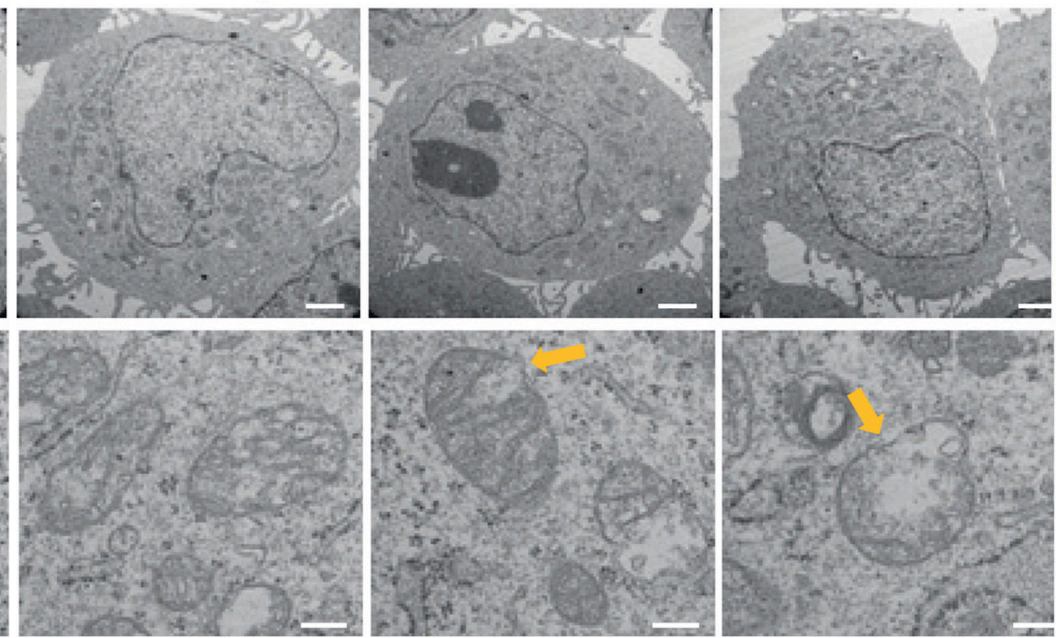

$20 \mathrm{~min}$

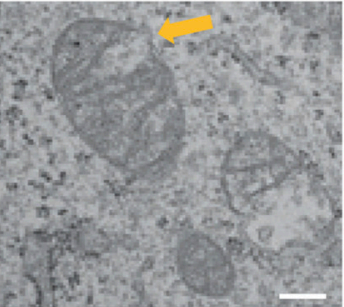

$1 \mathrm{~h}$

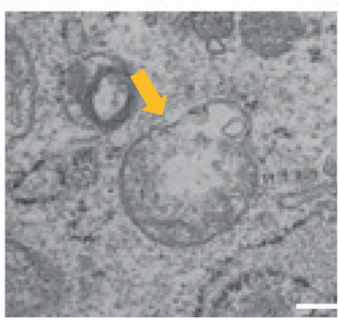

$3 \mathrm{~h}$

B BJeLR cells

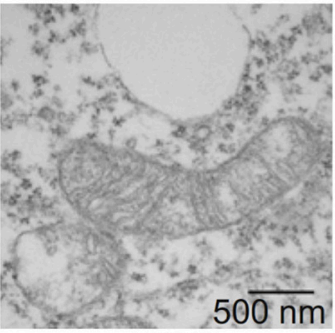

DMSO

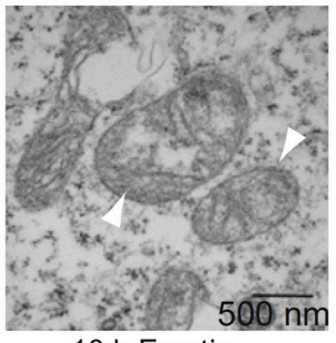

$10 \mathrm{~h}$ Erastin c Mouse embryonic fibroblasts

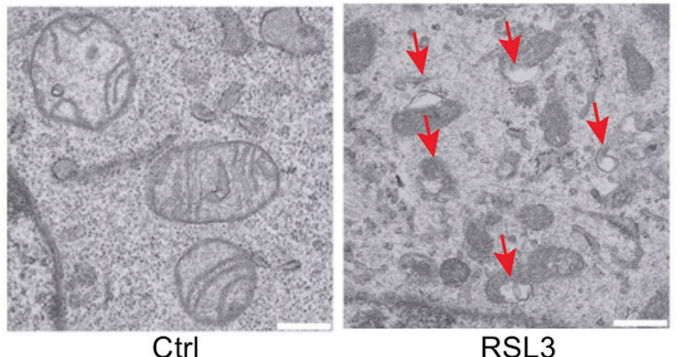

D

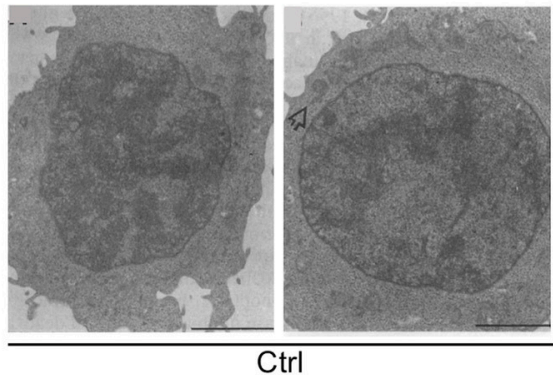

HT22 cells

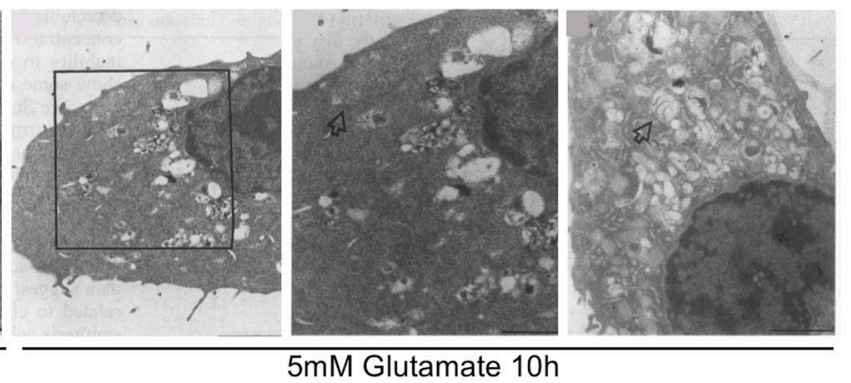

HT4 cells

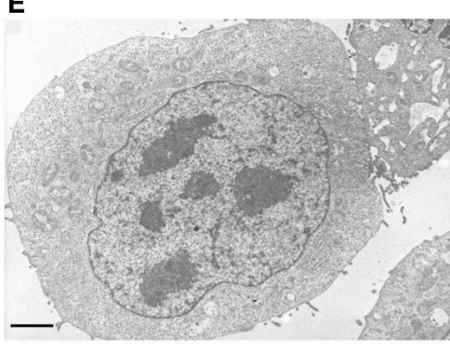

Ctrl

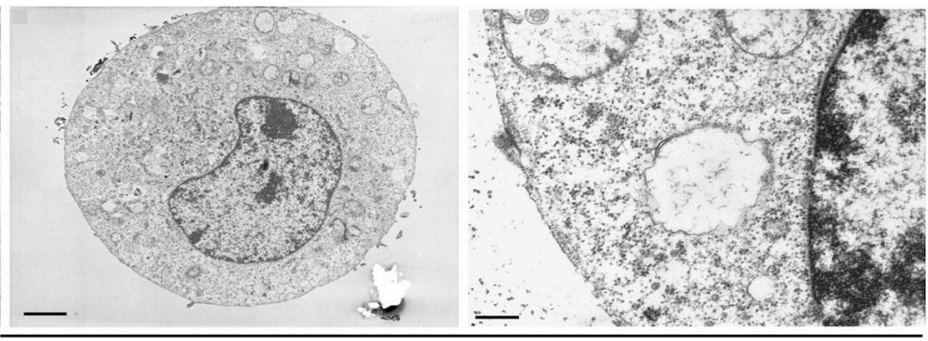

$10 \mathrm{mM}$ Glutamate 8h

FIGURE 1 | Ultrastructural changes in cells undergoing ferroptosis and oxytosis comprise prominent but diverse mitochondrial abnormalities while nuclear integrity is preserved. Electron micrographs of (A) mouse embryonic fibroblasts (MEF) showing a time-dependent outer mitochondrial membrane rupture (yellow arrows) upon 
FIGURE 1 | ferroptosis induction using RSL3 ( $50 \mathrm{nM}$; scale bars $2 \mu \mathrm{m}$ top row, $200 \mathrm{~nm}$ bottom row) while nuclear integrity is preserved, (B) of BJeLR cells treated with DMSO (10 h) or erastin (37 $\mathrm{M}, 10 \mathrm{~h})$ showing shrinkage and increased electron density of the mitochondria. (C) Similar morphological changes as in (B) in response to RSL3 in MEF. (D) HT22 cells after control treatment (panels 1/2) and after $5 \mathrm{mM}$ glutamate for $10 \mathrm{~h}$ (panels 3-5). Panels 3/4: low- and high-power micrographs, respectively, of the same region of the same cell. Arrows indicate mitochondria. Bars in panel $1=5 \mu \mathrm{m}$; panels 2,3 , and $5=2 \mu \mathrm{m}$; and panel $4=$ $1 \mu \mathrm{m}$. Glutamate-induced oxytosis is also characterized by preserved nuclear structure in addition to prominent swelling of the endoplasmic reticulum, Golgi apparatus and mitochondria as well as cytoplasmic vacuolization. Mitochondria showed loss of the cristae. (E) Oxytosis induced by glutamate in HT4 cells. (E, left) HT4 cells with no glutamate. Mitochondria have a regular shape and optical density. (E, middle and right) glutamate-treated cell (10 mM for $8 \mathrm{~h})$. The mitochondria appeared to be swollen and degraded with low optical density. Mitochondrial outer membrane disruption is observed. Scale bars $1.85 \mu \mathrm{m}$ (left and middle), $0.21 \mu \mathrm{m}$ (right). [Modified and reproduced with permission from (A) (Friedmann Angeli et al., 2014), (B) (Dixon et al., 2012), (C) (Doll et al., 2017), (D) (Tan et al., 1998b), and (E) (Tirosh et al., 2000)].

phosphatidylethanolamines containing arachidonic or adrenic acid, are formed.

\section{GLUTATHIONE PEROXIDASE 4-A KEY PLAYER IN FERROPTOSIS, IS ALSO RELEVANT IN OXYTOSIS}

The oxidized phosphatidylethanolamines that accumulate following activation of LOXs can be converted to their respective alcohols by GPX4 (Ursini et al., 1982) and thereby detoxified. As GPx4 depends on an adequate supply of GSH for its activity (Cozza et al., 2017), GSH depletion during oxytosis can be expected to impair GPX4 activity. Of note, the ferroptosis inducer erastin and GSH synthesis inhibitor BSO both induce GSH depletion associated with loss of GPX4 activity in cells sensitive to ferroptosis (Yang et al., 2014). As already mentioned above, genetic inactivation of GPX4 leads to the accumulation of lipid-ROS and a cell death pathway in MEF that shows a very similar pharmacological profile to oxytosis in HT22 cells (Seiler et al., 2008). RSL3, originally identified as a compound that induced cell death similar to that induced by erastin (Yang and Stockwell, 2008), was subsequently found to covalently interact with the active site selenocysteine of GPX4 to inhibit its enzymatic activity (Yang et al., 2016).

Overall, it seems that ultimately the inactivation of GPX4 leads to the same consequences as activation of LOX: accumulation of lipid-ROS in the inner leaflet of biomembranes. When system $\mathrm{x}_{\mathrm{c}}^{-}$ is inhibited in vitro, GSH depletion leads to activation of LOX and inactivation of GPX4, both of which are involved in oxytosis and ferroptosis. In addition, both processes might be linked as LOX activation requires the oxidation of its ferric iron to ferrous iron. This is facilitated when phospholipid hydroperoxides accumulate upon GPX4 inhibition (Conrad et al., 2007).

\section{ROS GENERATION IN OXYTOSIS AND FERROPTOSIS}

ROS generation is an essential step in oxytosis indicated by the fact that the lipophilic antioxidant $\alpha$-tocopherol is an efficient oxytosis inhibitor (Ishige et al., 2001b). In the initial phase of glutamate-induced oxytosis in HT22 cells, ROS levels increase, as detected by DCF fluorescence (Tan et al., 1998a). Although LOX might directly produce ROS, the major source of ROS during the exponential phase of accumulation appears to be complex I of the mitochondrial electron transport chain (Tan et al., 1998a). Along with DCF-detectable ROS accumulation, excessive mitochondrial superoxide production, as indicated by increased MitoSOX fluorescence, was also detected (Liu and Schubert, 2009). The mechanism of ROS production was identified as reverse electron transfer at the flavin mononucleotide group of complex I that could be prevented by the flavin protein inhibitor DPI in parallel with the inhibition of ROS production as detected by both ROS probes (Liu and Schubert, 2009). The necessity of mitochondrial ROS production for the execution of oxytosis in HT22 cells is exemplified by the observations that DPI as well as the mitochondrial uncoupler cyanide ptrifluoromethoxyphenylhydrazone (FCCP) protect nerve cells from oxytosis (Tan et al., 1998a; Liu and Schubert, 2009). In addition, high concentrations of the monoamine oxidase inhibitor clorgyline also block ROS production from complex I and cell death (Tan et al., 1998a) (Table 1). NADPH oxidase Nox4 (Ha et al., 2010) and lysosomes (Kubota et al., 2010) may also contribute to oxidative stress in oxytosis. However, although the accumulation of large amounts of intracellular ROS is thus a necessary step in oxytosis, it is not sufficient to cause death as cell death can be inhibited downstream of ROS accumulation ( $\mathrm{Li}$ et al., 1997a; Ishige et al., 2001b).

Induction of ferroptosis by erastin also induces ROS when measured by DCF fluorescence. Since antimycin A, a mitochondrial complex III inhibitor, partially suppressed erastininduced cell death, it was concluded that mitochondria-triggered ROS production is essential for erastin-induced ferroptosis (Yagoda et al., 2007). Interestingly, cells with increased sensitivity to ferroptosis show an increased level of basal ROS production (Yang et al., 2014) associated with an increased iron content (Yang and Stockwell, 2008). Upon induction of GSH depletion by either erastin or BSO, both hydrophilic ROS detected by DCF and lipid peroxides detected by BODIPY 581/591 C11 accumulate in ferroptosis-sensitive cells (Yang et al., 2014). During cell death in response to inducible GPX4 inactivation in MEF, lipid peroxidation clearly preceded the accumulation of hydrophilic ROS (Seiler et al., 2008). Surprisingly, erastin sensitivity was preserved in KRAS mutant 143B osteosarcoma cells lacking mitochondrial DNA (mtDNA)-encoded transcripts, which led to the hypothesis that ferroptosis might occur independently of mitochondrial ROS production (Dixon et al., 2012). However, mitochondrial DNA has been shown to be dispensable for menadione-induced mitochondrial ROS production and the mitochondrial apoptosis machinery (Jacobson et al., 1993; Marchetti et al., 1996). In addition, FCCP, a compound that inhibits oxytosis by blocking mitochondrial ROS production 
(Tan et al., 1998a), also inhibits ferroptosis (Maher et al., 2017). Similarly, clorgyline also protects from both erastin and RSL3 toxicity in HT22 cells (Table 1). Furthermore, other compounds that target mitochondrial proteins have been shown to inhibit ferroptosis including the glutaminase inhibitor compound 968 (Gao et al., 2015).

Upon electron microscopic examination, cells treated with ferroptosis inducers show prominent alterations in mitochondrial morphology (Yagoda et al., 2007; Dixon et al., 2012; Friedmann Angeli et al., 2014; Doll et al., 2017; Guo et al., 2017; Figures 1A-C). Moreover, a robust increase in MitoSOX fluorescence, an indicator of mitochondrial $\mathrm{H}_{2} \mathrm{O}_{2}$ production, was observed in cells treated with erastin (Neitemeier et al., 2017). Similar to oxytosis, ROS from sources other than mitochondria may also contribute to ferroptosis. Indeed, using the highly specific fluorescent probe LiperFluo that directly interacts with (phospho)lipid hydroperoxides, robust (phospho)lipid peroxidation could be localized to the endoplasmic reticulum during ferroptosis induced by RSL3 (Kagan et al., 2017). It is well-known that the endoplasmic reticulum can be a significant source of ROS, accounting for $\sim 25 \%$ of ROS production emanating from oxidative folding of proteins (Tu and Weissman, 2004). Finally, NOX1 activity has been reported to modulate lipid-ROS and the sensitivity to erastin in tumor cells (Xie et al., 2017).

Thus, the production of ROS, and in particular lipid peroxides, is an essential step in the cell death cascade for both ferroptosis and oxytosis. The contribution of different sources of ROS might vary between different cell types. Mitochondrial sources of non-lipid-ROS seem to be secondary to

TABLE 1 | Oxytosis and ferroptosis show an identical pharmacological profile.

\begin{tabular}{llll}
\hline Compound & \multicolumn{3}{c}{ Cell survival (\%) } \\
\hline & Oxytosis & \multicolumn{2}{c}{ Ferroptosis } \\
\cline { 2 - 4 } & Glutamate & Erastin & RSL3 \\
\hline No treatment & 13.5 & 10.0 & 12.2 \\
Clorgyline $(100 \mu \mathrm{M})$ & $86.4 \pm 8.7$ & $86.0 \pm 4.7$ & $95.4 \pm 7.1$ \\
Cycloheximide & $93.0 \pm 7.7$ & $98.0 \pm 11.3$ & 0.0 \\
Bafilomycin $(100 \mathrm{nM})$ & $88.7 \pm 1.3$ & $91.2 \pm 7.2$ & $60.3 \pm 4.8$ \\
Flt3 inhibitor $(1 \mu \mathrm{M})$ & $76.1 \pm 1.0$ & $69.8 \pm 1.3$ & $88.7 \pm 1.0$ \\
LY83583 $(1 \mu \mathrm{M})$ & $76.0 \pm 2.6$ & $81.1 \pm 2.6$ & $91.2 \pm 1.3$ \\
Apomorphine $(5 \mu \mathrm{M})$ & $86.9 \pm 1.0$ & $78.6 \pm 7.2$ & $90.7 \pm 4.2$ \\
CoCl $2(100 \mu \mathrm{M})$ & $77.8 \pm 1.1$ & $72.9 \pm 4.0$ & $76.4 \pm 6.8$ \\
Bl-6C9 $(10 \mu \mathrm{M})$ & $84.7 \pm 2.5$ & $78.7 \pm 8.1$ & $90.9 \pm 1.0$ \\
\end{tabular}

HT22 cells were treated for $24 \mathrm{~h}$ with glutamate $(5 \mathrm{mM})$, erastin $(0.5 \mu \mathrm{M})$, or RSL3 $(250 \mathrm{nM})$ alone (no treatment) or in the presence of the indicated concentrations of clorgyline, which inhibits mitochondrial ROS production (Tan et al., 1998a), the protein translation inhibitor cycloheximide, vacuolar $\mathrm{H}^{+}$-ATPase and autophagy inhibitor bafilomycin A, FMSlike tyrosine kinase 3 (Flt3) inhibitor III (Kang et al., 2014), the soluble guanylate cyclase inhibitor LY83583, inhibitors of calcium influx including the dopamine receptor D4 agonist apomorphine and cobalt chloride $\left(\mathrm{CoCl}_{2}\right)$ and the Bid inhibitor Bl-6C9. Cell survival was determined by the MTT assay and confirmed by visual inspection. Note that all compounds protect against oxytosis and ferroptosis induced by erastin. RSL3 also closely resembles these two compounds with the notable exception of cycloheximide. the generation of lipid hydroperoxides, the latter most probably generated by LOX activity. Whether LOX-induced changes of the mitochondrial outer membrane (van Leyen et al., 1998) directly induce mitochondrial non-lipid-ROS generation is currently unknown. The importance of lipid hydroperoxides as initiators of both ferroptotic and oxytotic cell death was underscored by the observation that the ferroptosis inhibitors ferrostatin-1, liproxstatin-1 as well as 1,8-tetrahydronaphthyridinol derivatives protect against ferroptosis induced by genetic GPX4 deletion in MEFs and glutamate-induced oxytosis in HT22 cells, correlating with their ability to prevent lipid peroxidation by trapping chaincarrying peroxyl radicals (Zilka et al., 2017).

\section{cGMP IN OXYTOSIS AND FERROPTOSIS}

Activated ALOX15, which generates various metabolites like 12and 15-HETE, might be involved in translating the increase in ROS into a calcium signal because soluble guanylate cyclase (sGC) is among the targets of these LOX metabolites (Brune and Ullrich, 1991). Inhibition of sGC by LY83583 blocks the execution of cell death by preventing the late calcium influx rather than GSH loss or ROS accumulation following glutamate treatment to initiate oxytosis (Li et al., 1997a). Correspondingly, cGMP levels peak after $6-8 \mathrm{~h}$ when GSH is depleted and ROS exponentially accumulate. In addition, the phosphodiesteraseresistant cGMP analog CPT-cGMP potentiates glutamateinduced oxytosis, even when added up to $8 \mathrm{~h}$ after treatment with glutamate ( $\mathrm{Li}$ et al., 1997a). Finally, cell death similar to oxytosis can be induced by CPT-cGMP (Henke et al., 2013). Thus, elevated cGMP levels eventually contribute to the opening of calcium channels resulting in a detrimental influx of calcium and finally cell death. Of note, the sGC inhibitor LY83583 not only protects against glutamate-induced oxytosis but also against erastin and RSL3 (Table 1).

\section{CALCIUM IN OXYTOSIS AND FERROPTOSIS}

During the exponential phase of ROS accumulation in oxytosis, there is a sharp increase in cellular calcium that immediately precedes cell death (Tan et al., 1998a). Of note, there is a mutual requirement for calcium and ROS for each to reach their maximal levels (Tan et al., 1998a). Even the first reports on the cell death pathway showed that oxytosis is efficiently inhibited by the calcium chelator EGTA in N18-RE-105 cells (Murphy et al., 1988). In addition, blockers of voltage-gated calcium channels (VGCC) such as $\mathrm{CdCl}_{2}$ completely prevented glutamate-induced oxytosis, while $\mathrm{MnCl}_{2}$ and $\mathrm{LaCl}_{2}$ reduced cell death by $\sim 50 \%$ (Murphy et al., 1988). Moreover, although dihydropyridine calcium channel inhibitors had little effect, inhibitors of L-type and T-type VGCC (Bergson et al., 2011) protected against oxytosis (Murphy et al., 1988). Of note, the protective activity of the general calcium channel inhibitor $\mathrm{CoCl}_{2}$ against glutamate-induced oxytosis is retained until the very late stage of the cell death pathway indicating the functional relevance of the late calcium accumulation for cell death execution ( $\mathrm{Li}$ 
et al., 1997a; Tan et al., 1998a). In addition, an inhibitor of store-operated calcium entry (SOCE), 2-aminoethoxydiphenyl borate, almost completely inhibited glutamate-induced oxytosis in HT22 cells with the same time profile as $\mathrm{CoCl}_{2}$ (Henke et al., 2013), indicating that SOCE might contribute to the final rise in cytosolic calcium during oxytosis. Indeed, siRNA-mediated knock-down of Orail, but not of other components of SOCE such as STIM1, STIM2, and TRPM7 protected against glutamateinduced oxytosis and decreased peaks of intracellular calcium immediately before cell rupture (Henke et al., 2013). The fact that CPT-cGMP induces calcium peaks similar to those observed in glutamate-induced oxytosis before cell lysis and ORAI1 knockdown is similarly protective against CPT-cGMP-induced cell death suggests that cGMP regulates calcium influx in oxytosis. However, the exact mechanism of how cGMP modulates SOCE in oxytosis remains to be fully characterized. Of note, the influence of SOCE on oxytosis might either be cell type-specific or long-term SOCE deficiency induces more complex changes as fibroblasts derived from STIM1, STIM2, and ORAI1 knock-out mice were reported to have an increased sensitivity to glutamateinduced oxytosis (Henke et al., 2012).

In contrast, the role of calcium in ferroptosis has not been fully explored. While some reports suggest that calcium has no impact on ferroptosis (Wolpaw et al., 2011), several compounds that reduce calcium influx, including $\mathrm{CoCl}_{2}$ (Tan et al., 1998a) and apomorphine (Ishige et al., 2001a), protect cells against death induced by both of the functionally different ferroptosis inducers erastin and RSL3 (Table 1).

\section{EXECUTION OF CELL DEATH IN FERROPTOSIS AND OXYTOSIS}

About $10-12 \mathrm{~h}$ after the induction of oxytosis, when both ROS and intracellular calcium levels have reached their maxima, the cells die (Tan et al., 2001b; Henke et al., 2013). The exact mechanisms underlying execution of cell death in oxytosis remain to be resolved. Ultrastructural examination revealed prominent morphological changes with swelling of the endoplasmic reticulum and the Golgi apparatus (Tan et al., 1998b; Figure 1D). Many cells appeared to contain large, cytoplasmic vacuoles associated with the rough endoplasmic reticulum and/or Golgi apparatus. In addition, the mitochondria, which retained both their outer and inner membranes, showed loss of their cristae. In contrast to these changes, the nucleus appeared largely unchanged without any signs of chromatin condensation or nuclear fragmentation, a hallmark of apoptosis (Tan et al., 1998b). Slightly different changes were observed in HT4 cells (Tirosh et al., 2000) where a prominent swelling of the mitochondria with cristaeolysis and outer membrane rupture was seen (Figure 1E). When observed by phase contrast light microscopy, the cells round up and first thin out their processes at $\sim 8 \mathrm{~h}$ after glutamate exposure (Tan et al., 1998b; Lewerenz et al., 2003) followed by cell shrinkage and frequent membrane blebbing prior to disintegration of the cell (Figure 2A). Corresponding to the sparing of the nuclei based upon ultrastructural analysis, internucleosomal DNA fragmentation cannot be detected during

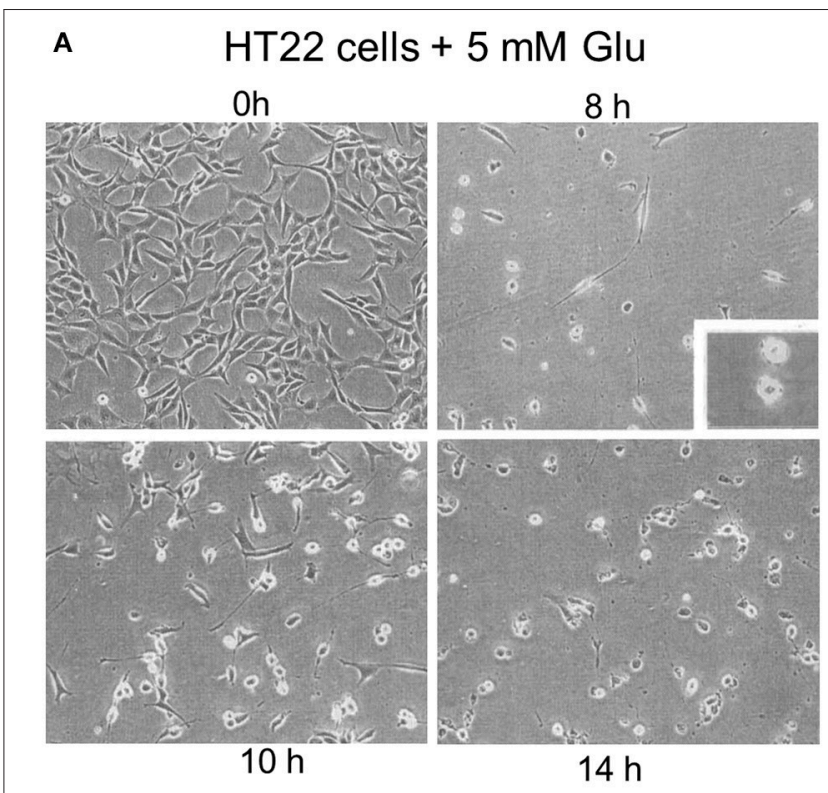

B

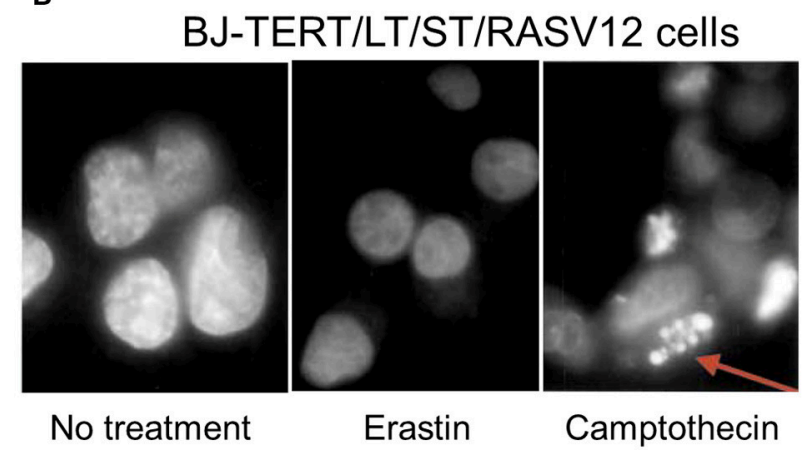

FIGURE 2 | Light microscopic changes of cellular shape during oxytosis and the nucleus during ferroptosis. (A) HT22 cells exposed for indicated durations to $5 \mathrm{mM}$ glutamate and observed by phase contrast microscopy. Cells were untreated (left upper) or treated with $5 \mathrm{mM}$ glutamate for $8 \mathrm{~h}$ (right upper), $10 \mathrm{~h}$ (left lower), or $14 \mathrm{~h}$ (right lower) before examination under a phase-contrast microscope. Inset in the right upper shows blebs on surface of cells. (B) Lack of prominent nuclear changes in erastin-treated BJ-TERT/LT/ST/RASV12 cells while camptothecin-treated cells display fragmented nuclei (arrow). [Modified and reproduced with permission from (A) (Tan et al., 1998b) and (B) (Dolma et al., 2003)].

oxytotic cell death in HT22 cells (Tan et al., 1998b). These observations are in line with the observation that caspase inhibitors that block apoptosis do not inhibit oxytosis (Tan et al., 1998b). In addition, the B-cell lymphoma protein 2 (Bcl-2) family member BAX has been excluded as part of the signaling cascade in oxytosis (Dargusch et al., 2001). BAX is transcriptionally upregulated by the tumor suppressor p53 (Selvakumaran et al., 1994) and upon death stimuli it dimerizes and inserts into the mitochondrial membrane to induce the mitochondrial pathway of apoptosis by mitochondrial outer membrane permeabilization (Cosentino and Garcia-Saez, 2017). Although spontaneous apoptosis was prominently decreased in primary neuronal 
cultures from BAX knock-out $\left(\mathrm{BAX}^{-/-}\right)$cells, no changes in the susceptibility to oxytosis were observed in immature $\mathrm{BAX}^{-/-}$ neurons compared to wild-type neurons (Dargusch et al., 2001). However, deficiency of another Bcl-2 family member, the antiapoptotic $\mathrm{Bcl}-\mathrm{x}_{\mathrm{L}}$, is associated with increased susceptibility to oxytosis although these cells show a compensatory increase in cellular GSH, most probably via an activated pentose phosphate pathway (Pfeiffer et al., 2017). This increased sensitivity in response to the absence of $\mathrm{Bcl}-\mathrm{x}_{\mathrm{L}}$ was associated with fragmented mitochondria, reduced mitochondrial respiratory capacity and mitochondrial ATP content and augmented basal ROS production. The anti-apoptotic protein $\mathrm{Bcl}-2$ has been found to be upregulated by stimulation of the cAMP pathway, which protects against oxytosis (Lewerenz et al., 2003; Sahin et al., 2006). Moreover, transient overexpression of $\mathrm{Bcl}-2$ protects against oxytosis in HT22 cells while siRNA-mediated Bcl-2 knock-down sensitizes the cells by increasing ROS production (Sahin et al., 2006). However, the precise mechanisms whereby classical modulators of apoptosis impact sensitivity to oxytosis still need further investigation. Interestingly, a non-canonical role of $\mathrm{Bcl}-2$ in ferroptosis has been described (see below) (Gascon et al., 2016) indicating that the effect of Bcl-2 family members on oxytosis might be independent of the anti-apoptotic functions of these proteins.

Another protein repeatedly reported to be involved in oxytosis is the pro-apoptotic AIF. AIF is a mitochondrial intermembrane protein that is released by mitochondrial outer membrane transition. In a caspase-independent manner, it causes large scale DNA fragmentation of $\sim 50 \mathrm{kB}$, chromatin condensation and finally nuclear fragmentation, as well as mitochondrial swelling and dissipation of the $\Delta \Psi_{\mathrm{m}}$, and exposure of phosphatidylserine on the outer layer of the plasma membrane, all hallmarks of classical apoptosis (Susin et al., 1999). As release of AIF from the mitochondria can be prevented by Bcl-2 (Susin et al., 1999), this might explain the protective action of $\mathrm{Bcl}-2$ in oxytosis. Moreover, calpain I has been shown to induce AIF release from the mitochondria and a prolonged increase of intracellular calcium, as present in oxytosis, can trigger calpain-mediated AIF translocation (Cao et al., 2007; Norberg et al., 2008). Calpain activation has been demonstrated during oxytosis in HT22 cells by some authors (Elphick et al., 2008). Some calpain inhibitors (ALLN and PD150606) have protective activity against oxytosis in HT22 cells (Elphick et al., 2008) while another (calpeptin) did not protect (Tan et al., 1998b). Thus, the role of calpains is still controversial.

Translocation of AIF has been observed during the execution of oxytosis by some investigators (Zhang and Bhavnani, 2006; Landshamer et al., 2008). The data published by Landshamer et al. support the idea that the truncated $\mathrm{BH} 3$-only domain protein Bid (tBid) translocates to the mitochondria, inducing AIF release and thereby cell death (Landshamer et al., 2008). Indeed, Bid can be processed to tBid directly by calpain (Cabon et al., 2012). This pathway from calcium increase to cell death via calpain activation, Bid processing and AIF release could explain the resistance of glutamate-induced oxytosis in HT22 cells to classical apoptosis inhibitors (Tan et al., 1998b; Landshamer et al., 2008).
However, it must be noted that there are some discrepancies that still need to be resolved until a role for AIF in oxytosis can be firmly established. Firstly, the Maher lab failed to detect large-scale DNA fragmentation, the indicator of AIF activity in the nucleus (Susin et al., 1999), during oxytosis (Tan et al., 1998b). Secondly, AIF was originally purified as a mitochondrial factor leading to chromatin condensation as well as nuclear fragmentation, hallmarks of classical apoptosis, in preparations of purified nuclei (Susin et al., 1996, 1999). In contrast, although some nuclear shrinkage might occur late in oxytosis, probably after the cells have disintegrated, the nucleus remains largely intact (Figures 1D,E) while prominent changes of the mitochondria and other organelles can be readily visualized by electron microscopy (Tan et al., 1998b; Figures 1D,E). Thus, in the absence of the two most important nuclear downstream effects of AIF, its involvement in oxytosis execution needs to be further characterized.

As reported for oxytosis, the structural changes during ferroptosis induced by erastin did not include changes in overt nuclear morphology characteristic of apoptosis (Dolma et al., 2003; Yagoda et al., 2007; Friedmann Angeli et al., 2014; Doll et al., 2017) although at late stages in the cell death process slight nuclear shrinkage was observed (Dolma et al., 2003; Seiler et al., 2008; Figure 2B). However, depending on the cell type, insult and the time of examination, prominent ultrastructural changes of the mitochondria were reported (Yagoda et al., 2007; Dixon et al., 2012; Friedmann Angeli et al., 2014; Doll et al., 2017) (Guo et al., 2017; Figures 1A-C). In line with the consistent lack of apoptotic changes of the nucleus, no cleavage-mediated activation of caspase 3 was observed during ferroptosis induced by erastin (Yagoda et al., 2007) or GPX4 depletion (Seiler et al., 2008), nor do caspase inhibitors protect (Seiler et al., 2008).

Interestingly, the cell death that occurs during direct astrocyte-to-neuron reprogramming is associated with lipid peroxidation and blocked by the ferroptosis inhibitors liproxstatin 1 and vitamin $\mathrm{E}$, which thus might represent ferroptosis (Gascon et al., 2016). Transduction with Bcl-2 protects against this type of cell death indicating that Bcl-2 may also have a protective role in ferroptosis (Gascon et al., 2016). However, mutant Bcl-2 that cannot interact and sequester with the pro-apoptotic Bcl-2 family members BAX and BAK proved to be more efficient at preventing cell death than wild-type Bcl-2 and mutants that show increased BAX/BAK interaction. Thus, it was concluded that $\mathrm{Bcl}-2$ in this context is protective in a non-canonical manner (Gascon et al., 2016). This finding is corroborated by the report that fibroblasts derived from BAX/BAK knock-out mice are equally susceptible to erastin-induced ferroptosis (Dixon et al., 2012). However, over-expression of $\mathrm{Bcl}-2$ did not protect fibroblasts against induction of ferroptosis in response to GPX4 inactivation (Seiler et al., 2008). Thus, the role of Bcl-2 in ferroptosis might be cell type-specific, depending on the insult that induces cell death and/or on the type of Bcl-2 used. In addition, similar to the described role in oxytosis, nuclear translocation of AIF has been reported during ferroptosis induced by GPX4 inactivation with siRNA-mediated knock-down being protective (Seiler et al., 2008). In addition, Bid knock-out HT22 cells are similarly 
resistant against glutamate and erastin-induced cell death (Neitemeier et al., 2017) and the Bid inhibitor BI-6C9 protects from both oxytosis and ferroptosis induced by either erastin or RSL3 (Table 1).

For p53, a tumor suppressor that plays a critical role in the checkpoint control of cells in response to a wide spectrum of DNA damaging or stress signals and apoptosis (Zhan et al., 1994; Rosemary Siafakas and Richardson, 2009), opposing roles have been reported, either promoting or inhibiting ferroptosis. Perhaps, the effects of p53 are context-dependent. In addition, while it has been proposed that dysfunctional p53 leads to upregulation of the cystine/glutamate antiporter system $\mathrm{x}_{\mathrm{c}}^{-}$in tumor cells and thereby to resistance against ferroptosis induced by oxidative stress (Jiang et al., 2015), pro-apoptotic nontranscriptional mechanisms induce sensitization of tumor cells to ferroptotic death in response to $\mathrm{p} 53$ deficiency by re-distribution of the dipeptidyl peptidase 4 to the plasma membrane and subsequent membrane lipid peroxidation (Xie et al., 2017).

\section{METABOLIC CHANGES AND ACTIVATION OF SIGNALING PATHWAYS DURING OXYTOSIS AND FERROPTOSIS}

The metabolic state of a cell has an important impact on its sensitivity to oxytosis. This is exemplified by the observation that cell density in proliferating cells is a critical regulator of oxytosis (Lewerenz et al., 2013). In addition, induction of eIF2 $\alpha$ phosphorylation as an adaptive mechanism to adjust the cellular metabolism in response to limitations of amino acids potently protects against oxytosis (Tan et al., 2001b; Lewerenz and Maher, 2009; Lewerenz et al., 2012). Correspondingly, arginase, an enzyme that catalyzes the degradation of arginine in the culture medium, has been identified as anti-oxytotic (Esch et al., 1998). Arginase treatment induces ATF4 in primary embryonic neurons and protects against oxytosis brought about by the system $\mathrm{x}_{\mathrm{c}}^{-}$ inhibitor homocysteate (Lange et al., 2008) although the same authors showed that induction of ATF4 during activation of oxytosis acts as a pro-death regulator (Lange et al., 2008).

Interestingly, increasing serum in the culture medium strongly enhances the sensitivity of HT22 cells to oxytosis induced by glutamate (Maher and Davis, 1996). Serum contains many growth factors and signaling molecules that may activate signaling pathways in cells thereby modifying the sensitivity to oxytosis (e.g., signaling via PI3K protects by increasing eIF $2 \alpha$ phosphorylation and ATF4 upregulation; Lewerenz et al., 2014). PI3K-mediated upregulation of SOD2 in response to resveratrol was also protective in oxytosis (Fukui et al., 2010). The prooxytotic factors in serum have not been investigated in depth.

Ferroptosis can be induced in MEF by amino acid deprivation in medium supplemented with serum (Gao et al., 2015). In this paradigm, cell death is induced by the absence of cystine in the medium which results in GSH depletion. The pro-death factors contained in serum in this paradigm were identified as transferrin, the carrier protein of iron, consistent with the view that iron is important in ferroptosis and, surprisingly, the amino acid glutamine. It was demonstrated that a product of glutamine metabolism, $\alpha$-ketoglutarate, mediates the pro-death effect of glutamine. However, how $\alpha$-ketoglutarate acts as a pro-ferroptotic factor remains to be resolved. Mitochondrial metabolism of $\alpha$-ketoglutarate is associated with ROS production through $\alpha$-ketoglutarate dehydrogenase and pyruvate dehydrogenase (Adam-Vizi and Starkov, 2010), indicating that increased levels of $\alpha$-ketoglutarate might directly increase ROS. Another change in the metabolism of cells after the initiation of ferroptosis by erastin-mediated system $\mathrm{x}_{\mathrm{c}}^{-}$ inhibition is the accumulation of the GSH analog ophthalmic acid (Skouta et al., 2014). The production of ophthalmic acid is catalyzed by the same enzymes that are involved in GSH synthesis with the exception that $\alpha$-aminobutyrate replaces cysteine. Ophthalmic acid, although redox inactive, may further decrease GSH synthesis by feed-back inhibition on GSH synthesizing enzymes (Kobayashi et al., 2017).

Another pathway that has been repeatedly reported to modify oxytotic cell death is the Ras-ERK pathway. However, the role of this pathway is still unclear. In 2000, two studies (Satoh et al., 2000; Stanciu et al., 2000) reported that ERK phosphorylation was increased in HT22 cells in response to glutamate treatment and that the MEK inhibitor U0126 could protect the cells from oxytosis. In contrast, a study published in 2001 (Maher, 2001) did not find an increase in glutamate-stimulated ERK phosphorylation in HT22 cells over the same time frame analyzed in the earlier studies and, more importantly, showed that two distinct MEK inhibitors, PD98059 and PD18452, did not prevent cell death. Interestingly, this latter observation was consistent with one of the earlier studies (Satoh et al., 2000), which also noted no effect of PD98059 on glutamate-induced cell death. In contrast, activation of ERK protected against oxytotic cell death (Maher, 2001). Both findings were recently replicated (Shibata et al., 2017).

Although the first study on erastin (Yagoda et al., 2007) found that ferroptosis could be completely blocked by MEK inhibition, a more recent study (Gao et al., 2015) has shown that this is likely due to the use of the MEK inhibitor U0126 in the earlier study. Unlike other MEK inhibitors, U0126 has anti-oxidant activity (Gao et al., 2015) and can protect cells against oxidative stress independently of its activity as an MEK inhibitor (Ong et al., 2015). Furthermore, UO126 also inhibits $\mathrm{p} 70^{\mathrm{S} 6 \mathrm{~K}}$, a kinase involved in protein translation (Fukazawa and Uehara, 2000). Modulation of translation has been repeatedly shown to protect against oxytosis and ferroptosis (Tan et al., 1998b; Yang and Stockwell, 2008; Dixon et al., 2012, Table 1 and see below). Thus, these results strongly suggest that any study that relies solely on U0126 is not reliable and that both oxytosis and ferroptosis do not require ERK activation. However, late ERK phosphorylation during oxytosis/ferrroptosis due to inactivation of phosphatases may occur in response to oxidative stress (Sen et al., 2012).

\section{MACROMOLECULAR SYNTHESIS DURING OXYTOSIS AND FERROPTOSIS}

Since inhibitors of both RNA and protein synthesis inhibit oxytosis in HT22 cells (Tan et al., 1998b), gene transcription 
and protein expression seem to be required for the execution of the cell death pathway. One of the genes induced during the course of oxytosis is GADD45 $\alpha$ (Choi et al., 2011), which encodes a nuclear protein induced by p53. During oxytosis, cJun N-terminal kinase (JNK) induces GADD45 $\alpha$ via p53 (Choi et al., 2011). Inhibition of JNK and knock-down of GADD $45 \alpha$ block the execution of oxytosis (Choi et al., 2011). Of note, GADD $45 \alpha$ functions as a heterochromatin relaxer (Chen et al., 2016) indicating that its expression might regulate additional genes important for the execution of oxytosis. However, others have argued that inhibition of protein synthesis simply reduces the consumption of cysteine, which would then be available for GSH biosynthesis (Ratan et al., 1994). In line with this assumption, phosphorylation of eIF $2 \alpha$, which is part of the multimeric eIF2 complex that is involved in the initiation of cap-dependent protein translation and the phosphorylation of which decreases cap-dependent translation (Wek et al., 2006), protects against oxytosis (Tan et al., 2001b; Lewerenz and Maher, 2009). However, under conditions that induced eIF $2 \alpha$-mediated cytoprotection, total protein synthesis was not perturbed in HT22 cells (Tan et al., 2001b). Moreover, the protection by eIF2 $\alpha$ phosphorylation is mediated by cap-independent translation of the nuclear factor ATF4 and subsequent upregulation of $\mathrm{xCT}$, the specific subunit of system $x_{c}^{-}$(Lewerenz and Maher, 2009). In addition, the argument that macromolecular synthesis inhibitors protect HT22 cells against oxytosis by shunting cysteine from protein synthesis to GSH synthesis was contradicted by the observation that these compounds also protect against oxytosis induced by treatment with BSO (Tan et al., 1998b).

Similar to oxytosis in HT22 cells, erastin-induced ferroptosis in three different cell lines, HT-1080, BJeLR, and Calu-1 cells as well as fibroblasts and HT22 cells was consistently blocked by the protein synthesis inhibitor cycloheximide (Yang and Stockwell, 2008; Dixon et al., 2012; Table 1). Cycloheximide, however, neither protects oncogenic human foreskin fibroblasts (Yang and Stockwell, 2008) nor HT22 cells (Table 1) from RSL3mediated GPX4 inhibition. These findings are fully consistent with protein synthesis being required early in the cell death pathway, downstream of inhibition of system $\mathrm{x}_{\mathrm{c}}^{-}$(Tan et al., 1998b) but upstream of GPX4 inhibition.

However, the downstream targets whose synthesis is inhibited by cycloheximide and thereby mediate its protective activity still need to be fully characterized. Prostaglandin-endoperoxide synthase 2 (PTGS2) expression, which encodes cyclooxygenase-2 (COX-2), is prominently upregulated during piperazine erastininduced ferroptosis (Yang et al., 2014), Targeted disruption of GPX4 in mouse skin in vivo (Sengupta et al., 2013) as well as GPX4 knock-down or its inhibition by RSL3 in tumor cells in vitro also induce robust PTGS2 expression (Seiler et al., 2008; Yang et al., 2014). However, COX-2 inhibition did not prevent erastin- or RSL3-induced ferroptosis (Sengupta et al., 2013). Thus, while COX-2 is not a cycloheximide target that mediates cell death, it might represent a marker for ferroptosis. Other transcripts highly upregulated in response to ferroptosis initiated by erastin include cation transport regulator-like protein 1 (CHAC1) (Dixon et al., 2014), a pro-apoptotic ER stress protein downstream of the pancreatic eIF2 $\alpha$-ATF4 pathway known to be upregulated by oxidized phospholipids (Mungrue et al., 2009), and DNA damage inducible transcript 4 (DDIT4) (Dixon et al., 2014), previously identified as part of the in vivo gene expression signature of oxidative stress (Han et al., 2008).

\section{AUTOPHAGY IN FERROPTOSIS AND OXYTOSIS}

As noted above, there is evidence that lysosomes contribute to ROS production in oxytosis (Kubota et al., 2010). However, while this study showed that multiple autophagy inhibitors could reduce both glutamate-induced ROS production and cell death, no activation of autophagy was seen. In contrast, others demonstrated a clear induction of autophagy by glutamate as indicated by a time-dependent increase in autophagosomebound LC3-II and loss of the LC3 binding protein and autophagy substrate p62 (Kim et al., 2009; Kumari et al., 2012).

Lysosomal ROS production was also recently shown to be involved in ferroptosis (Torii et al., 2016) where, identical to oxytosis, multiple autophagy inhibitors, such as bafilomycin A, blocked erastin- or RSL3-induced cell death. Similar results were obtained in HT22 cells (Table 1). This is in contrast to the original study on erastin that claimed that autophagy inhibitors did not prevent ferroptosis (Dixon et al., 2012) but is entirely consistent with several other recent studies that do show a requirement for autophagy in ferroptosis (Gao et al., 2016; Hou et al., 2016). Moreover, all of these recent studies have focused on the role of autophagy and lysosomes in modulating cellular iron levels since activation of autophagy is known to result in the turnover of the important iron-binding protein ferritin (a process known as ferritinophagy) (Biasiotto et al., 2016). Holoferritin is a multimeric protein comprised of 24 subunits consisting of both ferritin light polypeptide 1 (FTL1) and ferritin heavy polypeptide 1 (FTH1) and up to 4,500 molecules of $\mathrm{Fe}$ (III) in a redox inactive, inorganic form (Harrison and Arosio, 1996). However, during oxidative stress, iron can be released from ferritin in a redox active form, in part by copper-dependent mechanisms (Aliaga et al., 2011), inducing lipid peroxidation (Thomas et al., 1985). Thus, sequestering iron into holoferritin may be protective as illustrated by the observation that FTH1 is upregulated by $\mathrm{Nrf} 2$ in response to oxidative stress (Tsuji et al., 2000).

If redox active iron is released by ferritinophagy during the execution of oxytosis or ferroptosis, this should be associated with a decrease in ferritin protein subunits. However, the reports on this question are conflicting (Gao et al., 2016; Hou et al., 2016). This may be a reflection of different experimental conditions, release of iron in the absence of ferritin degradation or simply due to the focus on different ferritin subunits [FTL1 (Gao et al., 2016) vs. FTH1 (Hou et al., 2016)]. Consistent with these assumptions, transferrin has been identified as one of the serum factors that sensitizes cells to ferroptosis (Gao et al., 2015). Thus, there is ample evidence for a role for autophagy in both ferroptosis and oxytosis, probably involving ferritinophagy, but the precise nature of that role remains to be determined and may be cell-type dependent. 
However, since there is a potential for autophagy inducers to activate ferroptosis/oxytosis (see above), it seems that this idea needs to be carefully evaluated both in vitro and in vivo before this therapeutic strategy is pursued further.

\section{TRANSITION METALS IN FERROPTOSIS AND OXYTOSIS-CHALLENGING THE CONCEPT OF IRON-DEPENDENT CELL DEATH}

Transition metals like iron can catalyze the oxidation of biomolecules by Fenton chemistry (Halliwell, 1992), thereby contributing to the generation of ROS. The brain is characterized by a relatively high iron content and a dependence on mitochondrial respiration (Behl, 1999), which has long been taken as the argument that oxidative stress is highly relevant in CNS diseases (Beal, 1996). Thus, an iron-dependent form of cell death might be especially important in CNS diseases. As described above, the term ferroptosis was chosen due to the fact that (i) iron chelators block this type of cell death (Dixon et al., 2012), (ii) introduction of oncogenic mutations that sensitize cells to this type of cell death are associated with an increased intracellular iron content (Yang and Stockwell, 2008) and (iii) most importantly, transition metals other than iron reportedly failed to exacerbate this type of cell death (Dixon et al., 2012). Additionally, in a lentiviral screen, PHKG2, the catalytic subunit of the PHK (phosphorylase kinase) complex, was identified as a positive regulator of ferroptosis sensitivity by upregulating the intracellular iron pool (Yang et al., 2016) and, as discussed above, ferritinophagy might contribute to ferroptosis and oxytosis by releasing redox active iron.

Similarly to ferroptosis, oxytosis in HT22 cells can be inhibited by iron chelators (e.g., Liu and Schubert, 2009; Kang et al., 2014) and exacerbated by different sources of iron (Kang et al., 2014; Maher, 2017). As an alternative to blocking Fenton chemistry, it has been suggested that iron chelation can protect neurons against oxytosis by inducing hypoxia-incuble factor 1 signaling (Zaman et al., 1999; Soucek et al., 2003).

Thus, both oxytosis and ferroptosis show the same dependency on iron, further suggesting that both pathways are highly similar. However, the whole concept of ferroptosis was recently challenged by a study demonstrating that copper, the other important transition metal involved in redox metabolism in biological systems, influences both glutamate-induced oxytosis as well as erastin-mediated ferroptosis in HT22 cells to a similar extent as iron (Maher, 2017). Thus, at least under certain conditions, transition metals other than iron have the potential to exacerbate ferroptosis.

\section{GENE EXPRESSION PATTERNS ASSOCIATED WITH OXYTOSIS AND FERROPTOSIS RESISTANCE}

HT22 cells selected for resistance against oxytosis show a prominent increase in catalase expression as well as in the activity of GSH synthesizing enzymes but no expression changes in genes classically involved in apoptosis. These cells proved to be cross-resistant against GSH depletion by GCL inhibition, inhibition of GSH reductase and organic hydroperoxides (Sagara et al., 1998).

In other, independently generated glutamate-resistant HT22 cells, multiple mechanisms of oxytosis resistance were identified including ATF4-mediated upregulation of system $\mathrm{x}_{\mathrm{C}^{-}}$(Lewerenz et al., 2006, 2012), cooperative interaction of glutamate transporters with system $\mathrm{x}_{\mathrm{C}^{-}}$(Lewerenz et al., 2012), changes in mitochondrial metabolism and structure associated with ineffective energy metabolism but with an increased ability to maintain the mitochondrial membrane potential (Pfeiffer et al., 2013), increased expression of the mitochondrial protein GDAP1 (Noack et al., 2012), increased usage of glucose via the pentose phosphate pathway (Pfeiffer et al., 2013), reduction of SOCE (Henke et al., 2013), upregulation of signaling via G proteincoupled receptors (Sahin et al., 2006; Dittmer et al., 2008) and upregulation of aldehyde dehydrogenase $3 \mathrm{~A} 1$ as well as TIGR, a giant peroxisomal superoxide dismutase motif-containing protein (Toutzaris et al., 2010) also known as SZT2 (Frankel et al., 2009).

For ferroptosis, it has been reported that the level of expression of ASCL4 in part predicts sensitivity to this type of cell death (Yuan et al., 2016). Erastin-resistant DU-145 human prostate cancer cells are also resistant to the system $\mathrm{x}_{\mathrm{c}}^{-}$inhibitors sulfosalicylic acid and sorafenib (Dixon et al., 2014). The most upregulated genes in these cells were members of the aldoketo reductase family 1 (AKR1C1-3), enzymes that participate in the detoxification of toxic lipid metabolites (such as 4hydroxynonenal) generated downstream of the oxidation of various polyunsaturated fatty acid species (Burczynski et al., 2001). Thus, both the regulation of membrane phospholipid metabolism, e.g., by ACSL4, and also detoxification systems affect ferroptosis sensitivity.

To get a more comprehensive overview with regard to the mechanisms involved in ferroptosis and oxytosis resistance, we compared the transcriptome changes observed in glutamateresistant vs. glutamate-sensitive mouse HT22 cells (A. Methner, unpublished results) with those generated from erastin-resistant and -sensitive human DU-145 cells (Dixon et al., 2014). Analysis using the Panther classification system (Mi et al., 2013) of both gene lists (output signal $\geq 100$ and fold change $\geq \pm 2$ ) showed, when grouping the genes into biological processes, highly similar changes in the overlapping groups in both HT22R and erastinresistant cell lines (Dixon et al., 2014) when compared to their respective control cell lines (Figure 3).

\section{SUMMARY}

Conclusively, the molecular pathways involved in the regulation of ferroptosis and oxytosis share many similarities (Figure 4). Even the molecules reported to induce ferroptosis and oxytosis are either the same in the case of $\mathrm{BSO}$, or act via identical mechanisms, namely inhibition of cystine uptake by system $\mathrm{x}_{\mathrm{c}}^{-}$. In addition, the downstream players such as GPX4 and LOX and accumulation of mitochondria-derived ROS and nuclear translocation of AIF are identical. Moreover, transcriptomic changes in oxytosis and ferroptosis resistance correspond to 


\section{A HT22R vs HT22 control}

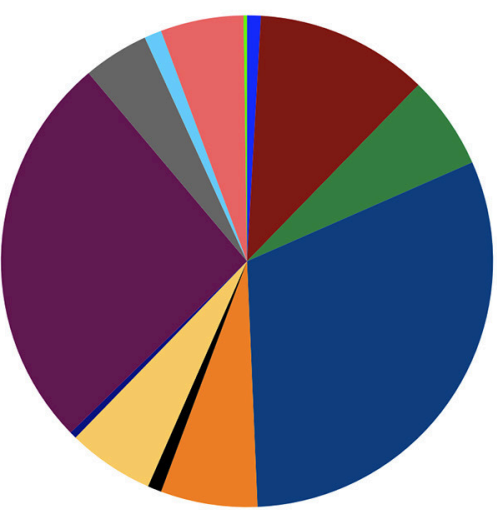

Total \# genes $=311$
0.91\% Biological adhesion (GO:0022610)

- $11.36 \%$ Biological regulation (GO:0065007)

- $6.14 \%$ Cellular component organization or biogenesis (GO: 0071840)

- $30.91 \%$ Cellular process (GO: 0009987)

6.36\% Developmental process (GO: 0032502)

- $0.91 \%$ Immune system process (GO: 0002376)

$5.68 \%$ Localization (GO: 0051179)

- $0.45 \%$ Locomotion (GO: 0040011)

- 26.14\% Metabolic process (GO: 0008152)

4.32\% Multicellular organismal process (GO: 0032501)

- 1.14\% Reproduction (GO: 0000003)

- 5.45\% Response to stimulus (GO: 0050896)

$0.23 \%$ Rhythmic process (GO: 0048511)

\section{B Erastin-resistant cell line vs control}

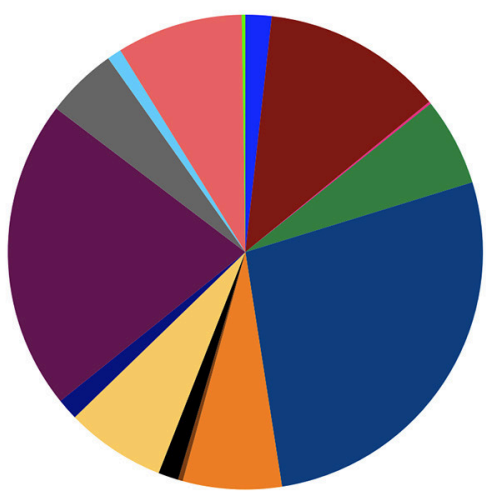

Total $\#$ genes $\mathbf{=} 880$
- $1.78 \%$ Biological adhesion (GO:0022610)

- $12.31 \%$ Biological regulation (GO:0065007)

0.16\% Cell killing (GO: 0001906)

- $5.99 \%$ Cellular component organization or biogenesis (GO: 0071840)

- $27.29 \%$ Cellular process (GO: 0009987)

6.72\% Developmental process (GO: 0032502)

$0.32 \%$ Growth (GO: 0040007)

- $1.38 \%$ Immune system process (GO: 0002376)

$6.80 \%$ Localization (GO: 0051179)

- 1.46\% Locomotion (GO: 0040011)

- $21.13 \%$ Metabolic process (GO: 0008152)

4.86\% Multicellular organismal process (GO: 0032501)

0.97\% Reproduction (GO: 0000003)

8.58\% Response to stimulus (GO: 0050896)

$0.24 \%$ Rhythmic process (GO: 0048511)

FIGURE 3 | Transcriptome changes in acquired oxytosis and ferroptosis resistance. The transcriptomes of HT22 cells selected for resistance to oxytosis induced by glutamate (HT22R) (A) and DU-145 human prostate cancer cells selected for resistance against ferroptosis induced by erastin (B) (Dixon et al., 2014) were compared to their parental oxytosis/ferroptosis sensitive cell lines. Using the Panther classification system, deregulated genes (= fold-change $\geq \pm 2$ ) are grouped into biological processes. Both cell lines have highly similar deregulation profiles, even though the total number of deregulated genes differs greatly. The erastin-resistant cell line shows (minor) deregulation in only two additional processes compared to the HT22R. These processes (cell killing and cell growth) are likely to be attributed to the cancerous origin of this cell line. Gene Ontology (GO) identifications are shown between brackets.

identical pathways. Some characteristics have been studied in more detail under the name of either oxytosis or ferroptosis, e.g., the role of cGMP and calcium during oxytosis and the generation of lipid peroxides during ferroptosis.

In our opinion, the discrepancies that have been described in the scientific literature do not indicate that ferroptosis and oxytosis are different pathways of regulated cell death but rather result from methodological differences or cell type-specific variations on a single theme. Thus, oxytosis and ferroptosis should be regarded as two names for the same cell death pathway. As it has recently become clear than not only iron but also copper is a prominent metal regulator of oxytosis/ferroptosis (Maher, 2017), the term ferroptosis might be too narrowly conceived. However, that ROS play an important role in this type of cell death-as expressed by the term oxytosis-is generally accepted.

\section{IS OXYTOSIS/FERROPTOSIS RELEVANT IN DISEASES OF THE CENTRAL NERVOUS SYSTEM?}

\section{Non-apoptotic Regulated Cell Death in Human Brain and Animal Models of Neurological Disease}

Terminal transferase dUTP nick-end labeling (TUNEL) (McCarthy and Evan, 1998), a histochemical marker of DNA fragmentation and therefore cell death, has been reported in 


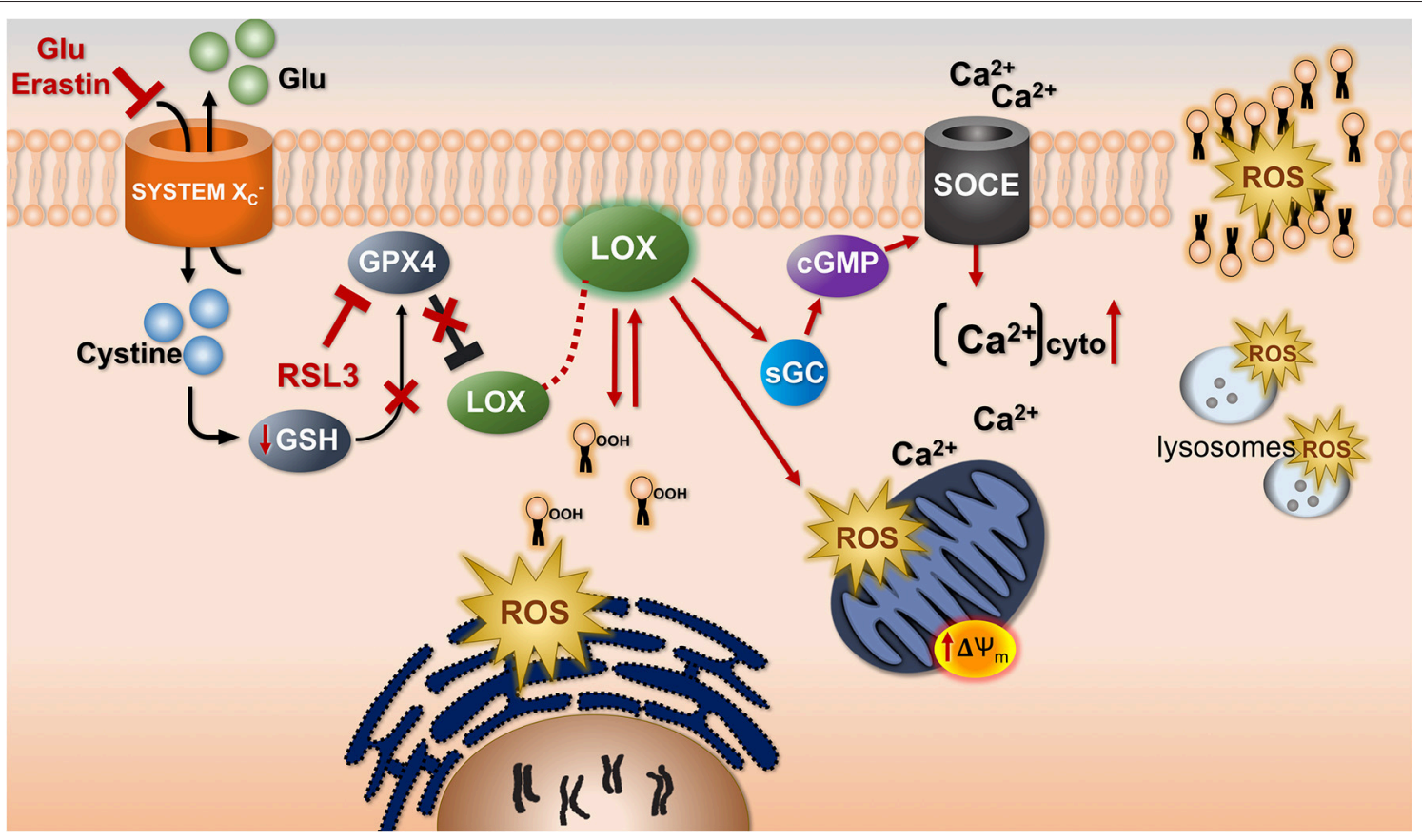

FIGURE 4 | The common cell death pathway in oxytosis and ferroptosis. Uptake of cystine by system $x_{C}^{-}$associated with counter-transport of glutamate (Glu) is inhibited by Glu and Erastin. This leads to depletion of glutathione (GSH) and subsequently inhibition of the GSH-dependent enzyme GSH peroxidase 4 (GPX4). GPX4 can also be directly inhibited by RSL3. GPX4 inhibition leads to activation of LOX. As a result, lipid hydroperoxides (lipid icons with OOH) accumulate probably in or very close to the endoplasmic reticulum as the initiating step of the production of reactive oxygen species (ROS). There is exponentially increasing mitochondrial ROS production associated with a hyperpolarization of the mitochondrial membrane potential $(\Delta \Psi \mathrm{m})$. Whether this is a direct effect of LOX is unknown. However, via activation of soluble guanylate cyclase (sGC) induced by LOX metabolites cGMP accumulates and calcium influx through store-operated calcium channels (SOCE) is

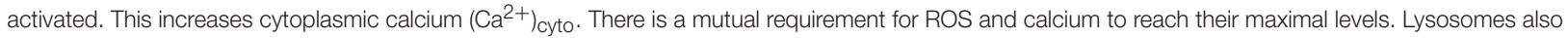
contribute to the overall ROS production.

many diseases of the CNS including AD (reviewed by Behl, 2000), HD (Portera-Cailliau et al., 1995), ALS (Ekegren et al., 1999), and ischemic stroke (Endres et al., 1998). However, in AD TUNEL-positive cells were found to be only inconsistently associated with other structural features of apoptosis (reviewed by Behl, 2000). Correspondingly, increased neuronal nuclear localization of AIF was demonstrated in the brain regions most severely affected by AD pathology (Yu et al., 2010; Lee et al., 2012). In vitro, $A \beta$ has been found to induce both necrosis (Behl et al., 1994) and apoptosis (Forloni et al., 1993) in neuronal cells. Interestingly, iron has been reported to be upregulated in the cortex of patients with $\mathrm{AD}$ upon high-resolution MRI in vivo (van Rooden et al., 2015) and ex vivo as well as in histochemical stainings (Bulk et al., 2018).

In cerebral ischemia, regulated cell death is thought to predominate in ischemic border zones, the so-called penumbra, in part by glutamate excitotoxicity (reviewed in Dirnagl et al., 1999). The detection of internucleosomal DNA fragmentation and the reduction in tissue damage by caspase inhibitors indicate that, at least in part, classical apoptosis is triggered by cerebral ischemia (Endres et al., 1998). However, AIF translocation has also been reported following cerebral ischemia (reviewed in Ferrer and Planas, 2003). Correspondingly, reduced AIF expression (Culmsee et al., 2005) has been shown to mitigate ischemic cell death in animal models of stroke. Moreover, excitotoxic neuronal cell death induced by glutamate in vivo is to some extent mediated by oxytosis in vitro (Schubert and Piasecki, 2001).

Transient global cerebral ischemia in rodents is a model of neuronal damage in response to hypoxia or cardiac arrest in humans. Global ischemia results in selective delayed neuronal death with region-specific differences in hypoxia sensitivity (reviewed in Schmidt-Kastner, 2015). When mild, it predominantly results in a delayed degeneration of the neurons of the CA1 subregion of the hippocampus. There has been a decades-long debate whether delayed neuronal degeneration in response to global ischemia represents necrosis, apoptosis or a type of delayed cell death that combines elements of both (reviewed in Martin et al., 1998; Schmidt-Kastner, 2015). However, the ultrastructural changes in neurons in response to global ischemia are very different from neuronal apoptosis (Martin et al., 1998). In addition, hypoxia-induced delayed neuronal cell death is associated with increased lipid peroxidation (Perez Velazquez et al., 2006) and activation of LOXs (Yigitkanli et al., 2017). Biphasic mitochondrial ROS production was reported which can be inhibited by antioxidants and iron chelation in association with neuroprotection (Park et al., 2011). Calpain I activation as well AIF have are reported to play a role (Cao et al., 2007), and calcium chelation (Calderone et al., 2004) and inhibition of SOCE (Zhang et al., 2014) protect. Execution of delayed neuronal cell death is associated with upregulation of PTGS2 mRNA and COX-2 protein (Nakayama 
et al., 1998). Furthermore, accumulation of blood-derived iron has been observed in post-hypoxic brain, which contributes to delayed oxidative stress and neuronal cell death (Park et al., 2011). Finally, this type of cell death depends on macromolecular synthesis as inhibitors of protein translation as well as gene transcription protect (Goto et al., 1990; Shigeno et al., 1990; Deshpande et al., 1992). In summary, while suggestive, whether delayed hypoxic neuronal death represents oxytosis/ferroptosis requires further investigation.

$\mathrm{PD}$ is characterized by a progressive degeneration of midbrain dopaminergic neurons in the substantia nigra (SN) and iron accumulation and GSH loss have been repeatedly observed in autoptic PD SN (Dexter et al., 1989; Jellinger et al., 1990; Sian et al., 1994; Fitzmaurice et al., 2003). Moreover, iron levels, as detected by magnetic resonance imaging, are upregulated in presymptomatic stages of PD (Pyatigorskaya et al., 2015) and pilot data indicate that iron chelation might be therapeutically beneficial in PD patients (Devos et al., 2014). The fact that dopamine metabolism is linked to the production of ROS (Anderson et al., 2011) and surrogate markers of oxidative stress are present in PD (Buhmann et al., 2004) indicates the potential pathophysiological relevance of oxidative stress in $\mathrm{PD}$. Moreover, the differential susceptibility of SN dopaminergic neurons depending on their calcium buffering capacity as mediated by calbindin expression (Yamada et al., 1990) has led to the view that calcium might contribute to dopaminergic neuronal death in PD. Thus, iron, GSH, oxidative stress and calcium might all contribute to neurodegeneration in $\mathrm{PD}$, an observation highly suggestive for an involvement of oxytosis/ferroptosis.

In transgenic mice expressing mutant SOD1 (the classical animal model for ALS), caspase 1 and 3 activation have been reported, and consequently caspase inhibition was shown to reduce motor neuron death ( $\mathrm{Li}$ et al., 2000; Chi et al., 2007). In contrast, another study reported that motor neuron degeneration in SOD1 mutant mice resembles slow necrosis without evidence of caspase activation (Martin et al., 2007). Additionally, astrocytes derived from familial ALS patients are able to induce motor neuron cell death via Ripk1 dependent necroptosis in vitro (Re et al., 2014) and necroptosis plays a role in axonal degeneration in ALS in vivo (Ito et al., 2016). However, AIF nuclear translocation is seen in motor neurons from patients with sporadic ALS (Shibata et al., 2009), as well as in SOD1 mutant transgenic mice (Oh et al., 2006; Chi et al., 2007). Of note, spinal cord iron accumulation has been reported in mouse models of ALS, mutant SOD1 ${ }^{\text {G37R }}$ (Jeong et al., 2009) and SOD1 ${ }^{\text {G93A }}$ (Lee et al., 2015) mice. In human ALS, high-resolution MRI revealed iron accumulation in the motor cortex in vivo and well as in autoptic brain, in the latter confirmed by iron histochemistry (Kwan et al., 2012)

Ultrastructural analysis of both brain tissue from HD patients, a neurodegenerative disease caused by a CAG repeat expansion in the huntingtin gene (HTT), and mice expressing the first exon of HTT with increased CAG repeats showed shrunken, degenerating neurons, which did not display the nuclear fragmentation typical of apoptosis (Turmaine et al., 2000). Another study described upregulation of PARP1 in HD brains, whereas activated caspase 3 was only rarely observed (Vis et al., 2005). Fibroblasts derived from HD patients are more susceptible to oxytosis (Archer and Mancall, 1983), and ferroptosis inhibitors rescue mutant HTT-induced cell death in cellular HD models (Skouta et al., 2014). Last but not least, also in HD there is abundant iron accumulation, especially in the basal ganglia, correlating with disease severity (Penney et al., 1997; Dominguez et al., 2016).

Despite this contradictory evidence, huge numbers of studies have suggested that apoptosis is a major hallmark of neurodegeneration. The vast majority of these studies have relied solely on the detection of TUNEL-positive cells. However, since TUNEL staining does not allow one to discriminate between the internucleosomal DNA cleavage that is typical of apoptosis and large-scale DNA fragmentation as induced by AIF or EndoG and seen in other regulated cell death paradigms, unequivocal assignment of apoptotic or non-apoptotic regulated cell death in diseased brain is challenging (Charriaut-Marlangue and BenAri, 1995). The issue is further complicated by the lack of specific markers for the recently described non-apoptotic forms of regulated cell death with the exception of necroptosis (staining for phospho-MLKL in human cells and tissues; Sun et al., 2012).

In light of the only very recent recognition of non-apoptotic forms of regulated cell death in brain diseases and the limitation of TUNEL staining for apoptotic cell death, it is conceivable that some, if not to say the majority, of these processes proceed through non-apoptotic cell death paradigms. Interestingly, there is ample evidence that oxidative stress plays an important role in ALS (Barber and Shaw, 2010), AD (Bonda et al., 2010), ischemic stroke (Shivakumar et al., 1995), and HD (Stack et al., 2008). In addition, iron accumulation occurs in ALS, AD, PD, and $\mathrm{HD}$ in brain regions affected most in the individual diseases (Kwan et al., 2012; Pyatigorskaya et al., 2015; van Rooden et al., 2015; Dominguez et al., 2016; Bulk et al., 2018) as well as in the posthypoxic brain (Park et al., 2011). Thus, novel types of regulated non-apoptotic cell death that encompass oxidative stress as a critical step and are facilitated by transition metals (i.e., oxytosis/ferroptosis) are strong candidates and are possibly highly relevant for many neurodegenerative diseases.

\section{EVIDENCE FOR IN VIVO RELEVANCE OF OXYTOSIS/FERROPTOSIS}

\section{Genetic Models for Induction of Oxytosis/Ferroptosis}

The majority of research that has addressed the role of oxytosis/ferroptosis in vivo has relied on inducible genetic GPX4 deletion either in whole animals or specific tissues (Angeli et al., 2017). Global, inducible GPX4 deletion resulted in acute renal failure and death within two weeks (Friedmann Angeli et al., 2014). This was associated with increased levels of lipid peroxidation in both mitochondrial and extra-mitochondrial compartments and could be delayed by treatment with the oxytosis/ferroptosis inhibitor liproxstatin-1. In a similar model of global inducible GPX4 deletion, rapid death was associated with neuronal loss restricted to the CA1 region of the hippocampus (Yoo et al., 2012). In contrast, in a neuron-specific noninducible knock-out mouse, neuronal loss was most prominent 
in the CA3 region of the hippocampus and involved mainly GABAergic interneurons (Seiler et al., 2008). Neuronal loss was associated with intense astrogliosis (Seiler et al., 2008; Yoo et al., 2012) indicating that oxytotic/ferroptotic death is-in stark contrast to apoptosis-pro-inflammatory. Forebrain neuron-specific conditional deletion of GPX4 did not lead to rapid death but rather a delayed loss of hippocampal neurons in the absence of detectable caspase activation, which was associated with progressive deficits in spatial learning and memory (Hambright et al., 2017). Neuronal death was exacerbated by vitamin E deficiency, while liproxstatin-1 blunted this effect. Surprisingly, inducible global neuron-specific GPX4 deletion in adult mice caused rapid death due to spinal motor neuron degeneration, while neurons in the cerebral cortex remained unaffected at the time of death (Chen et al., 2015). Interestingly, conditional deletion of GPX4 in hypothalamic neuronal subpopulations [proopiomelanocortin (POMC) and agouti-related protein (AgRP) positive neurons] as well as in dopaminergic neurons did not result in overt neuronal loss (Schriever et al., 2017). In summary, the induction of oxytosis/ferroptosis by genetic GPX4 deletion relies on the timing of the deletion and whether it is restricted to specific cell types, e.g., neurons. In addition, dietary content of vitamin $\mathrm{E}$ might also modify the phenotype of GPX4 deletion.

In contrast to the genetic deletion of GPX4, deletion of $\mathrm{xCT}$ is not associated with an overt phenotype (Sato et al., 2005) and although xCT is expressed in the brain (Shih et al., 2006), no increase in oxidative stress or neuronal loss has been observed in these mice (De Bundel et al., 2011). This is in stark contrast to $\mathrm{xCT}$-deficient cells in cell culture, which rapidly die from oxytosis/ferroptosis when antioxidants are omitted from the culture medium (Sato et al., 2005). This paradox is easily explained by the fact that cells in culture strongly rely on cystine in the culture medium since cysteine is readily oxidized to cystine in regular culture conditions (Lewerenz et al., 2013). In vivo, the oxygen concentrations in tissues are much lower and thus uptake of reduced cysteine can compensate for the lack of cystine uptake by system $\mathrm{x}_{\mathrm{c}}^{-}$(Sato et al., 2005). Correspondingly, no overt phenotype of pharmacological system $\mathrm{x}_{\mathrm{c}}^{-}$inhibition was observed after subcutaneous or intravenous delivery of erastin or its more stable analog piperazine erastin in athymic nude mice, although tumor growth was retarded indicating that in vivo tumor cells are sensitive to oxytotic/ferroptotic cell death induced by system $\mathrm{x}_{\mathrm{c}}^{-}$inhibition (Yang et al., 2014). However, it remains unknown whether and to what extent erastin and piperazine erastin cross the blood-brain barrier. Thus, with the exception of tumor cells, oxytosis/ferroptosis in vivo is more likely to be induced by GPX4 inhibition rather than system $\mathrm{x}_{\mathrm{c}}^{-}$inhibition.

\section{PHARMACOLOGICAL EVIDENCE FOR OXYTOSIS/FERROPTOSIS IN CNS DISEASES}

Since ferrostatin-1 and liproxstatin-1 protect against erastinand RSL3-induced oxytosis/ferroptosis, but not against staurosporine-induced apoptosis or necroptosis (Dixon et al., 2012; Friedmann Angeli et al., 2014), they have been employed to demonstrate that ferroptotic/oxytotic neuronal death occurs in in vitro and in vivo models of neurological diseases.

Ballistic transfection of rat striatal slices with mutant HTT exon 1 induced loss of medium spiny neurons expressing mutant HTT that could be inhibited by ferrostatin-1 (Skouta et al., 2014). In addition, ischemic neuronal death induced by transient middle cerebral artery occlusion, a stroke model in mice, was substantially reduced by liproxstatin-1 (Tuo et al., 2017). Markers of ferroptosis, including increased lipid hydroperoxides, decreased GSH, decreased GPX4 activity and upregulation of PTGS2 are present in association with neuronal cell death in organotypic hippocampal slice cultures treated with hemoglobin, an in vitro model of intracerebral hemorrhage (ICH) (Li et al., 2017). In addition, neuronal death could be inhibited by ferrostatin-1. Similar observations were made in animal models of ICH suggesting that ferroptosis at least in part explains the delayed neuronal death that occurs after this insult.

With regard to $\mathrm{PD}$, it was reported recently that human differentiated midbrain neurons are uniquely sensitive to oxytosis/ferroptosis brought about by erastin treatment in comparison to insults that induce apoptotic or autophagic cell death (Do Van et al., 2016). Moreover, both ferrostatin-1 and the iron chelator deferiprone reduced dopaminergic degeneration in animal models of PD (Devos et al., 2014; Do Van et al., 2016) and improved motor function in PD patients (Devos et al., 2014).

\section{FUTURE PERSPECTIVES}

In summary, multi-layered evidence strongly suggests that oxytosis/ferroptosis plays an important role in CNS diseases. We conclude that oxytosis and ferroptosis are one single pathway. Combining accumulated research performed under both terms will therefore accelerate our understanding of this type of cell death. Most importantly, more specific tools are needed to unequivocally demonstrate where and when neurons undergo oxytosis/ferroptosis in different CNS pathologies. This will provide the necessary framework for clinical trials with oxytosis/ferroptosis inhibitors that are under development for treatment of neurodegenerative diseases.

\section{AUTHOR CONTRIBUTIONS}

JL: provided the concepts for the review and wrote much of it; PM: wrote a portion of the review and revised the manuscript critically for important intellectual content; GA: wrote parts of the manuscript, performed the gene expression analysis, revised the manuscript critically for important intellectual content; $\mathrm{MC}$ and AM: contibuted substatiantially to the conception of the manuscript and revised it critically for important intellectual content. 


\section{FUNDING}

PM was supported by AI104034 from NIH and a grant from the Edward N. \& Della L. Thome Memorial

\section{REFERENCES}

Adam-Vizi, V., and Starkov, A. A. (2010). Calcium and mitochondrial reactive oxygen species generation: how to read the facts. J. Alzheimers Dis. 20(Suppl. 2), S413-S426. doi: 10.3233/JAD-2010-100465

Aliaga, M. E., Carrasco-Pozo, C., Lopez-Alarcon, C., Olea-Azar, C., and Speisky, H. (2011). Superoxide-dependent reduction of free $\mathrm{Fe}(3+)$ and release of $\mathrm{Fe}(2+)$ from ferritin by the physiologically-occurring $\mathrm{Cu}(\mathrm{I})$-glutathione complex. Bioorg. Med. Chem. 19, 534-541. doi: 10.1016/j.bmc.2010.10.064

Anderson, D. G., Mariappan, S. V., Buettner, G. R., and Doorn, J. A. (2011). Oxidation of 3,4-dihydroxyphenylacetaldehyde, a toxic dopaminergic metabolite, to a semiquinone radical and an ortho-quinone. J. Biol. Chem. 286, 26978-26986. doi: 10.1074/jbc.M111.249532

Andrabi, S. A., Kim, N. S., Yu, S. W., Wang, H., Koh, D. W., Sasaki, M., et al. (2006). Poly(ADP-ribose) (PAR) polymer is a death signal. Proc. Natl. Acad. Sci. U.S.A. 103, 18308-18313. doi: 10.1073/pnas.0606526103

Andrabi, S. A., Umanah, G. K., Chang, C., Stevens, D. A., Karuppagounder, S. S., Gagne, J. P., et al. (2014). Poly(ADP-ribose) polymerase-dependent energy depletion occurs through inhibition of glycolysis. Proc. Natl. Acad. Sci. U.S.A. 111, 10209-10214. doi: 10.1073/pnas.1405158111

Angeli, J. P. F., Shah, R., Pratt, D. A., and Conrad, M. (2017). Ferroptosis inhibition: mechanisms and opportunities. Trends Pharmacol. Sci. 38, 489-498. doi: 10.1016/j.tips.2017.02.005

Archer, F. J., and Mancall, E. L. (1983). Cultured fibroblasts in Huntington's disease. I. Effects of L-glutamic acid. Arch. Neurol. 40, 19-23. doi: 10.1001/archneur.1983.04050010039009

Banjac, A., Perisic, T., Sato, H., Seiler, A., Bannai, S., Weiss, N., et al. (2008). The cystine/cysteine cycle: a redox cycle regulating susceptibility versus resistance to cell death. Oncogene 27, 1618-1628. doi: 10.1038/sj.onc.1210796

Bannai, S., and Kitamura, E. (1980). Transport interaction of L-cystine and L-glutamate in human diploid fibroblasts in culture. J. Biol. Chem. 255, 2372-2376.

Barber, S. C., and Shaw, P. J. (2010). Oxidative stress in ALS: key role in motor neuron injury and therapeutic target. Free Radic. Biol. Med. 48, 629-641. doi: 10.1016/j.freeradbiomed.2009.11.018

Beal, M. F. (1996). Mitochondria, free radicals, and neurodegeneration. Curr. Opin. Neurobiol. 6, 661-666. doi: 10.1016/S0959-4388(96)80100-0

Behl, C. (1999). Alzheimer's disease and oxidative stress: implications for novel therapeutic approaches. Prog. Neurobiol. 57, 301-323. doi: 10.1016/S0301-0082(98)00055-0

Behl, C. (2000). Apoptosis and Alzheimer's disease. J. Neural Transm. 107, 1325-1344. doi: 10.1007/s007020070021

Behl, C., Davis, J. B., Klier, F. G., and Schubert, D. (1994). Amyloid beta peptide induces necrosis rather than apoptosis. Brain Res. 645, 253-264. doi: 10.1016/0006-8993(94)91659-4

Bergmann, O., Spalding, K. L., and Frisen, J. (2015). Adult Neurogenesis in Humans. Cold Spring Harb. Perspect. Biol. 7:a018994. doi: 10.1101/cshperspect.a018994

Bergson, P., Lipkind, G., Lee, S. P., Duban, M. E., and Hanck, D. A. (2011). Verapamil block of T-type calcium channels. Mol. Pharmacol. 79, 411-419. doi: 10.1124/mol.110.069492

Bhardwaj, R. D., Curtis, M. A., Spalding, K. L., Buchholz, B. A., Fink, D., Bjork-Eriksson, T., et al. (2006). Neocortical neurogenesis in humans is restricted to development. Proc. Natl. Acad. Sci. U.S.A. 103, 12564-12568. doi: 10.1073/pnas.0605177103

Biasiotto, G., Di Lorenzo, D., Archetti, S., and Zanella, I. (2016). Iron and neurodegeneration: is ferritinophagy the link? Mol. Neurobiol. 53, 5542-5574. doi: $10.1007 /$ s12035-015-9473-y
Foundation. MC received funding from the Deutsche Forschungsgemeinschaft (DFG; CO 291/2-3 and CO 291/51) and the Human Frontier Science Program (HFSP) RGP0013. $\mathrm{MC}$ and AM were supported by the DFG program SPP 1710.

Bonda, D. J., Wang, X., Perry, G., Nunomura, A., Tabaton, M., Zhu, X., et al. (2010). Oxidative stress in Alzheimer disease: a possibility for prevention. Neuropharmacology 59, 290-294. doi: 10.1016/j.neuropharm.2010.04.005

Brune, B., and Ullrich, V. (1991). 12-hydroperoxyeicosatetraenoic acid inhibits main platelet functions by activation of soluble guanylate cyclase. Mol. Pharmacol. 39, 671-678.

Buhmann, C., Arlt, S., Kontush, A., Moller-Bertram, T., Sperber, S., Oechsner, M., et al. (2004). Plasma and CSF markers of oxidative stress are increased in Parkinson's disease and influenced by antiparkinsonian medication. Neurobiol. Dis. 15, 160-170. doi: 10.1016/j.nbd.2003.10.003

Bulk, M., Abdelmoula, W. M., Nabuurs, R. J. A., van der Graaf, L. M., Mulders, C. W. H., Mulder, A. A., et al. (2018). Postmortem MRI and histology demonstrate differential iron accumulation and cortical myelin organization in early- and late-onset Alzheimer's disease. Neurobiol. Aging 62, 231-242. doi: 10.1016/j.neurobiolaging.2017.10.017

Burczynski, M. E., Sridhar, G. R., Palackal, N. T., and Penning, T. M. (2001). The reactive oxygen species-and Michael acceptor-inducible human aldoketo reductase AKR1C1 reduces the alpha,beta-unsaturated aldehyde 4hydroxy-2-nonenal to 1,4-dihydroxy-2-nonene. J. Biol. Chem. 276, 2890-2897. doi: 10.1074/jbc.M006655200

Cabon, L., Galan-Malo, P., Bouharrour, A., Delavallee, L., Brunelle-Navas, M. N., Lorenzo, H. K., et al. (2012). BID regulates AIF-mediated caspase-independent necroptosis by promoting BAX activation. Cell Death Differ. 19, 245-256. doi: $10.1038 /$ cdd.2011.91

Calderone, A., Jover, T., Mashiko, T., Noh, K. M., Tanaka, H., Bennett, M. V., et al. (2004). Late calcium EDTA rescues hippocampal CA1 neurons from global ischemia-induced death. J. Neurosci. 24, 9903-9913. doi: 10.1523/JNEUROSCI.1713-04.2004

Cao, G., Xing, J., Xiao, X., Liou, A. K., Gao, Y., Yin, X. M., et al. (2007). Critical role of calpain I in mitochondrial release of apoptosisinducing factor in ischemic neuronal injury. J. Neurosci. 27, 9278-9293. doi: 10.1523/JNEUROSCI.2826-07.2007

Carter, G. W., Young, P. R., Albert, D. H., Bouska, J., Dyer, R., Bell, R. L., et al. (1991). 5-lipoxygenase inhibitory activity of zileuton. J. Pharmacol. Exp. Ther. 256, 929-937.

Charriaut-Marlangue, C., and Ben-Ari, Y. (1995). A cautionary note on the use of the TUNEL stain to determine apoptosis. Neuroreport 7, 61-64. doi: 10.1097/00001756-199512000-00014

Chen, K., Long, Q., Wang, T., Zhao, D., Zhou, Y., Qi, J., et al. (2016). Gadd45a is a heterochromatin relaxer that enhances iPS cell generation. EMBO Rep. 17, 1641-1656. doi: 10.15252/embr.201642402

Chen, L., Hambright, W. S., Na, R., and Ran, Q. (2015). Ablation of the ferroptosis inhibitor glutathione peroxidase 4 in neurons results in rapid motor neuron degeneration and paralysis. J. Biol. Chem. 290, 28097-28106. doi: 10.1074/jbc.M115.680090

Chi, L., Ke, Y., Luo, C., Gozal, D., and Liu, R. (2007). Depletion of reduced glutathione enhances motor neuron degeneration in vitro and in vivo. Neuroscience 144, 991-1003. doi: 10.1016/j.neuroscience.2006.09.064

Chillaron, J., Font-Llitjos, M., Fort, J., Zorzano, A., Goldfarb, D. S., Nunes, V., et al. (2010). Pathophysiology and treatment of cystinuria. Nat. Rev. Nephrol. 6, 424-434. doi: 10.1038/nrneph.2010.69

Choi, H. J., Kang, K. S., Fukui, M., and Zhu, B. T. (2011). Critical role of the JNK-p53-GADD45alpha apoptotic cascade in mediating oxidative cytotoxicity in hippocampal neurons. Br. J. Pharmacol. 162, 175-192. doi: 10.1111/j.1476-5381.2010.01041.x

Christofferson, D. E., and Yuan, J. (2010). Necroptosis as an alternative form of programmed cell death. Curr. Opin. Cell Biol. 22, 263-268. doi: 10.1016/j.ceb.2009.12.003 
Clement, F., and Belleville, S. (2010). Compensation and disease severity on the memory-related activations in mild cognitive impairment. Biol. Psychiatry 68, 894-902. doi: 10.1016/j.biopsych.2010.02.004

Conrad, M., Angeli, J. P., Vandenabeele, P., and Stockwell, B. R. (2016). Regulated necrosis: disease relevance and therapeutic opportunities. Nat. Rev. Drug Discov. 15, 348-366. doi: 10.1038/nrd.2015.6

Conrad, M., Schneider, M., Seiler, A., and Bornkamm, G. W. (2007). Physiological role of phospholipid hydroperoxide glutathione peroxidase in mammals. Biol. Chem. 388, 1019-1025. doi: 10.1515/BC.2007.130

Cosentino, K., and Garcia-Saez, A. J. (2017). Bax and bak pores: are we closing the circle? Trends Cell Biol. 27, 266-275. doi: 10.1016/j.tcb.2016.11.004

Cozza, G., Rossetto, M., Bosello-Travain, V., Maiorino, M., Roveri, A., Toppo, S., et al. (2017). Glutathione peroxidase 4-catalyzed reduction of lipid hydroperoxides in membranes: the polar head of membrane phospholipids binds the enzyme and addresses the fatty acid hydroperoxide group toward the redox center. Free Radic. Biol. Med. 112, 1-11. doi: 10.1016/j.freeradbiomed.2017.07.010

Culmsee, C., Zhu, C., Landshamer, S., Becattini, B., Wagner, E., Pellecchia, M., et al. (2005). Apoptosis-inducing factor triggered by poly(ADP-ribose) polymerase and Bid mediates neuronal cell death after oxygen-glucose deprivation and focal cerebral ischemia. J. Neurosci. 25, 10262-10272. doi: 10.1523/JNEUROSCI.2818-05.2005

Dargusch, R., Piasecki, D., Tan, S., Liu, Y., and Schubert, D. (2001). The role of Bax in glutamate-induced nerve cell death. J. Neurochem. 76, 295-301. doi: 10.1046/j.1471-4159.2001.00035.x

Davis, J. B., and Maher, P. (1994). Protein kinase C activation inhibits glutamateinduced cytotoxicity in a neuronal cell line. Brain Res. 652, 169-173. doi: 10.1016/0006-8993(94)90334-4

De Bundel, D., Schallier, A., Loyens, E., Fernando, R., Miyashita, H., Van Liefferinge, J., et al. (2011). Loss of system $\mathrm{x}(\mathrm{c})$ - formula does not induce oxidative stress but decreases extracellular glutamate in hippocampus and influences spatial working memory and limbic seizure susceptibility. J. Neurosci. 31, 5792-5803. doi: 10.1523/JNEUROSCI.5465-10.2011

Degterev, A., Huang, Z., Boyce, M., Li, Y., Jagtap, P., Mizushima, N., et al. (2005). Chemical inhibitor of nonapoptotic cell death with therapeutic potential for ischemic brain injury. Nat. Chem. Biol. 1, 112-119. doi: 10.1038/nchembio711

Deshpande, J., Bergstedt, K., Linden, T., Kalimo, H., and Wieloch, T. (1992). Ultrastructural changes in the hippocampal CA1 region following transient cerebral ischemia: evidence against programmed cell death. Exp. Brain Res. 88, 91-105. doi: 10.1007/BF02259131

Devos, D., Moreau, C., Devedjian, J. C., Kluza, J., Petrault, M., Laloux, C., et al. (2014). Targeting chelatable iron as a therapeutic modality in Parkinson's disease. Antioxid. Redox Signal. 21, 195-210. doi: 10.1089/ars.2013.5593

de Wit, J., Bakker, L. A., van Groenestijn, A. C., van den Berg, L. H., Schroder, C. D., Visser-Meily, J. M., et al. (2017). Caregiver burden in amyotrophic lateral sclerosis: a systematic review. Palliat. Med. 32, 231-245. doi: $10.1177 / 0269216317709965$.

Dexter, D. T., Wells, F. R., Lees, A. J., Agid, F., Agid, Y., Jenner, P., et al. (1989). Increased nigral iron content and alterations in other metal ions occurring in brain in Parkinson's disease. J. Neurochem. 52, 1830-1836. doi: 10.1111/j.1471-4159.1989.tb07264.x

Dirnagl, U., Iadecola, C., and Moskowitz, M. A. (1999). Pathobiology of ischaemic stroke: an integrated view. Trends Neurosci. 22, 391-397. doi: 10.1016/S0166-2236(99)01401-0

Dittmer, S., Sahin, M., Pantlen, A., Saxena, A., Toutzaris, D., Pina, A. L., et al. (2008). The constitutively active orphan G-protein-coupled receptor GPR39 protects from cell death by increasing secretion of pigment epithelium-derived growth factor. J. Biol. Chem. 283, 7074-7081. doi: 10.1074/jbc.M704323200

Dixon, S. J., Lemberg, K. M., Lamprecht, M. R., Skouta, R., Zaitsev, E. M., Gleason, C. E., et al. (2012). Ferroptosis: an iron-dependent form of nonapoptotic cell death. Cell 149, 1060-1072. doi: 10.1016/j.cell.2012.03.042

Dixon, S. J., Patel, D. N., Welsch, M., Skouta, R., Lee, E. D., Hayano, M., et al. (2014). Pharmacological inhibition of cystine-glutamate exchange induces endoplasmic reticulum stress and ferroptosis. Elife 3:e02523. doi: 10.7554/eLife.02523

Doll, S., Proneth, B., Tyurina, Y. Y., Panzilius, E., Kobayashi, S., Ingold, I., et al. (2017). ACSL4 dictates ferroptosis sensitivity by shaping cellular lipid composition. Nat. Chem. Biol. 13, 91-98. doi: 10.1038/nchembio.2239
Dolma, S., Lessnick, S. L., Hahn, W. C., and Stockwell, B. R. (2003). Identification of genotype-selective antitumor agents using synthetic lethal chemical screening in engineered human tumor cells. Cancer Cell 3, 285-296. doi: 10.1016/S1535-6108(03)00050-3

Domaradzki, J. (2015). The impact of huntington disease on family carers: a literature overview. Psychiatr. Pol. 49, 931-944. doi: 10.12740/PP/34496

Dominguez, J. F., Ng, A. C., Poudel, G., Stout, J. C., Churchyard, A., Chua, P., et al. (2016). Iron accumulation in the basal ganglia in Huntington's disease: crosssectional data from the IMAGE-HD study. J. Neurol. Neurosurg. Psychiatr. 87, 545-549. doi: 10.1136/jnnp-2014-310183

Dondelinger, Y., Declercq, W., Montessuit, S., Roelandt, R., Goncalves, A., Bruggeman, I., et al. (2014). MLKL compromises plasma membrane integrity by binding to phosphatidylinositol phosphates. Cell Rep. 7, 971-981. doi: 10.1016/j.celrep.2014.04.026

Do Van, B., Gouel, F., Jonneaux, A., Timmerman, K., Gele, P., Petrault, M., et al. (2016). Ferroptosis, a newly characterized form of cell death in Parkinson's disease that is regulated by PKC. Neurobiol. Dis. 94, 169-178. doi: 10.1016/j.nbd.2016.05.011

Ekegren, T., Grundstrom, E., Lindholm, D., and Aquilonius, S. M. (1999). Upregulation of Bax protein and increased DNA degradation in ALS spinal cord motor neurons. Acta Neurol. Scand. 100, 317-321. doi: 10.1111/j.1600-0404.1999.tb00403.x

Elphick, L. M., Hawat, M., Toms, N. J., Meinander, A., Mikhailov, A., Eriksson, J. E., et al. (2008). Opposing roles for caspase and calpain death proteases in L-glutamate-induced oxidative neurotoxicity. Toxicol. Appl. Pharmacol. 232, 258-267. doi: 10.1016/j.taap.2008.07.008

Endres, M., Namura, S., Shimizu-Sasamata, M., Waeber, C., Zhang, L., Gomez-Isla, T., et al. (1998). Attenuation of delayed neuronal death after mild focal ischemia in mice by inhibition of the caspase family. $J$. Cereb. Blood Flow Metab. 18, 238-247. doi: 10.1097/00004647-19980300000002

Esch, F., Lin, K. I., Hills, A., Zaman, K., Baraban, J. M., Chatterjee, S., et al. (1998). Purification of a multipotent antideath activity from bovine liver and its identification as arginase: nitric oxide-independent inhibition of neuronal apoptosis. J. Neurosci. 18, 4083-4095.

Ferrer, I., and Planas, A. M. (2003). Signaling of cell death and cell survival following focal cerebral ischemia: life and death struggle in the penumbra. $J$. Neuropathol. Exp. Neurol. 62, 329-339. doi: 10.1093/jnen/62.4.329

Fitzmaurice, P. S., Ang, L., Guttman, M., Rajput, A. H., Furukawa, Y., and Kish, S. J. (2003). Nigral glutathione deficiency is not specific for idiopathic Parkinson's disease. Mov. Disord. 18, 969-976. doi: 10.1002/mds.10486

Forloni, G., Chiesa, R., Smiroldo, S., Verga, L., Salmona, M., Tagliavini, F., et al. (1993). Apoptosis mediated neurotoxicity induced by chronic application of beta amyloid fragment 25-35. Neuroreport 4, 523-526. doi: 10.1097/00001756-199305000-00015

Frankel, W. N., Yang, Y., Mahaffey, C. L., Beyer, B. J., and O'Brien, T. P. (2009). Szt2, a novel gene for seizure threshold in mice. Genes Brain Behav. 8, 568-576. doi: 10.1111/j.1601-183X.2009.00509.x

Friedmann Angeli, J. P., Schneider, M., Proneth, B., Tyurina, Y. Y., Tyurin, V. A., Hammond, V. J., et al. (2014). Inactivation of the ferroptosis regulator Gpx4 triggers acute renal failure in mice. Nat. Cell Biol. 16, 1180-1191. doi: $10.1038 /$ ncb3064

Fuchs, Y., and Steller, H. (2011). Programmed cell death in animal development and disease. Cell 147, 742-758. doi: 10.1016/j.cell.2011.10.033

Fukazawa, H., and Uehara, Y. (2000). U0126 reverses Ki-ras-mediated transformation by blocking both mitogen-activated protein kinase and p70 S6 kinase pathways. Cancer Res. 60, 2104-2107.

Fukui, M., Choi, H. J., and Zhu, B. T. (2010). Mechanism for the protective effect of resveratrol against oxidative stress-induced neuronal death. Free Radic. Biol. Med. 49, 800-813. doi: 10.1016/j.freeradbiomed.2010.06.002

Gao, M., Monian, P., Pan, Q., Zhang, W., Xiang, J., and Jiang, X. (2016). Ferroptosis is an autophagic cell death process. Cell Res. 26, 1021-1032. doi: 10.1038/cr.2016.95

Gao, M., Monian, P., Quadri, N., Ramasamy, R., and Jiang, X. (2015). Glutaminolysis and transferrin regulate ferroptosis. Mol. Cell 59, 298-308. doi: 10.1016/j.molcel.2015.06.011

Gascon, S., Murenu, E., Masserdotti, G., Ortega, F., Russo, G. L., Petrik, D., et al. (2016). Identification and successful negotiation of a metabolic 
checkpoint in direct neuronal reprogramming. Cell Stem Cell 18, 396-409. doi: 10.1016/j.stem.2015.12.003

Goto, K., Ishige, A., Sekiguchi, K., Iizuka, S., Sugimoto, A., Yuzurihara, M., et al. (1990). Effects of cycloheximide on delayed neuronal death in rat hippocampus. Brain Res. 534, 299-302. doi: 10.1016/0006-8993(90)90144-Z

Guo, J., Xu, B., Han, Q., Zhou, H., Xia, Y., Gong, C., et al. (2017). Ferroptosis: a novel anti-tumor action for cisplatin. Cancer Res. Treat. doi: 10.4143/crt.2016.572. [Epub ahead of print].

Ha, J. S., Lim, H. M., and Park, S. S. (2010). Extracellular hydrogen peroxide contributes to oxidative glutamate toxicity. Brain Res. 1359, 291-297. doi: 10.1016/j.brainres.2010.08.086

Halliwell, B. (1992). Reactive oxygen species and the central nervous system. J. Neurochem. 59, 1609-1623. doi: 10.1111/j.1471-4159.1992.tb10990.x

Hambright, W. S., Fonseca, R. S., Chen, L., Na, R., and Ran, Q. (2017). Ablation of ferroptosis regulator glutathione peroxidase 4 in forebrain neurons promotes cognitive impairment and neurodegeneration. Redox Biol. 12, 8-17. doi: 10.1016/j.redox.2017.01.021

Han, E. S., Muller, F. L., Perez, V. I., Qi, W., Liang, H., Xi, L., et al. (2008). The in vivo gene expression signature of oxidative stress. Physiol. Genomics 34, 112-126. doi: 10.1152/physiolgenomics.00239.2007

Handley, E. E., Pitman, K. A., Dawkins, E., Young, K. M., Clark, R. M., Jiang, T. C., et al. (2017). Synapse dysfunction of layer V pyramidal neurons precedes neurodegeneration in a mouse model of TDP- 43 proteinopathies. Cereb. Cortex 27, 3630-3647. doi: 10.1093/cercor/bhw185

Harrison, P. M., and Arosio, P. (1996). The ferritins: molecular properties, iron storage function and cellular regulation. Biochim. Biophys. Acta 1275, 161-203. doi: 10.1016/0005-2728(96)00022-9

Hayes, D., Wiessner, M., Rauen, T., and McBean, G. J. (2005). Transport of L-[14C]cystine and L-[14C]cysteine by subtypes of high affinity glutamate transporters over-expressed in HEK cells. Neurochem. Int. 46, 585-594. doi: 10.1016/j.neuint.2005.03.001

Henke, N., Albrecht, P., Bouchachia, I., Ryazantseva, M., Knoll, K., Lewerenz, J., et al. (2013). The plasma membrane channel ORAI1 mediates detrimental calcium influx caused by endogenous oxidative stress. Cell Death Dis. 4:e470. doi: 10.1038/cddis.2012.216

Henke, N., Albrecht, P., Pfeiffer, A., Toutzaris, D., Zanger, K., and Methner, A. (2012). Stromal interaction molecule 1 (STIM1) is involved in the regulation of mitochondrial shape and bioenergetics and plays a role in oxidative stress. $J$. Biol. Chem. 287, 42042-42052. doi: 10.1074/jbc.M112.417212

Herculano-Houzel, S. (2009). The human brain in numbers: a linearly scaled-up primate brain. Front. Hum. Neurosci. 3:31. doi: 10.3389/neuro.09.031.2009

Herms, J., and Dorostkar, M. M. (2016). Dendritic spine pathology in neurodegenerative diseases. Annu. Rev. Pathol. 11, 221-250. doi: 10.1146/annurev-pathol-012615-044216

Holler, N., Zaru, R., Micheau, O., Thome, M., Attinger, A., Valitutti, S., et al. (2000). Fas triggers an alternative, caspase-8-independent cell death pathway using the kinase RIP as effector molecule. Nat. Immunol. 1, 489-495. doi: 10.1038/82732

Hou, W., Xie, Y., Song, X., Sun, X., Lotze, M. T., Zeh, H. J. III, et al. (2016). Autophagy promotes ferroptosis by degradation of ferritin. Autophagy 12, 1425-1428. doi: 10.1080/15548627.2016.1187366

Ishige, K., Chen, Q., Sagara, Y., and Schubert, D. (2001a). The activation of dopamine D4 receptors inhibits oxidative stress-induced nerve cell death. J. Neurosci. 21, 6069-6076.

Ishige, K., Schubert, D., and Sagara, Y. (2001b). Flavonoids protect neuronal cells from oxidative stress by three distinct mechanisms. Free Radic. Biol. Med. 30, 433-446. doi: 10.1016/S0891-5849(00)00498-6

Ito, Y., Ofengeim, D., Najafov, A., Das, S., Saberi, S., Li, Y., et al. (2016). RIPK1 mediates axonal degeneration by promoting inflammation and necroptosis in ALS. Science 353, 603-608. doi: 10.1126/science.aaf6803

Jackson, J. S., Witton, J., Johnson, J. D., Ahmed, Z., Ward, M., Randall, A. D., et al. (2017). Altered Synapse Stability in the Early Stages of Tauopathy. Cell Rep. 18, 3063-3068. doi: 10.1016/j.celrep.2017.03.013

Jacobson, M. D., Burne, J. F., King, M. P., Miyashita, T., Reed, J. C., and Raff, M. C. (1993). Bcl-2 blocks apoptosis in cells lacking mitochondrial DNA. Nature 361, 365-369. doi: 10.1038/361365a0

Jellinger, K., Paulus, W., Grundke-Iqbal, I., Riederer, P., and Youdim, M. B. (1990). Brain iron and ferritin in Parkinson's and Alzheimer's diseases. J. Neural Transm. Park. Dis. Dement. Sect. 2, 327-340. doi: 10.1007/BF02252926
Jeong, S. Y., Rathore, K. I., Schulz, K., Ponka, P., Arosio, P., and David, S. (2009). Dysregulation of iron homeostasis in the CNS contributes to disease progression in a mouse model of amyotrophic lateral sclerosis. J. Neurosci. 29, 610-619. doi: 10.1523/JNEUROSCI.5443-08.2009

Jiang, L., Kon, N., Li, T., Wang, S. J., Su, T., Hibshoosh, H., et al. (2015). Ferroptosis as a p53-mediated activity during tumour suppression. Nature 520, 57-62. doi: $10.1038 /$ nature 14344

Jisaka, M., Kim, R. B., Boeglin, W. E., Nanney, L. B., and Brash, A. R. (1997). Molecular cloning and functional expression of a phorbol esterinducible 8S-lipoxygenase from mouse skin. J. Biol. Chem. 272, 24410-24416. doi: $10.1074 / j b c .272 .39 .24410$

Jouan-Lanhouet, S., Arshad, M. I., Piquet-Pellorce, C., Martin-Chouly, C., Le Moigne-Muller, G., Van Herreweghe, F., et al. (2012). TRAIL induces necroptosis involving RIPK1/RIPK3-dependent PARP-1 activation. Cell Death Differ. 19, 2003-2014. doi: 10.1038/cdd.2012.90

Kagan, V. E., Mao, G., Qu, F., Angeli, J. P., Doll, S., Croix, C. S., et al. (2017). Oxidized arachidonic and adrenic PEs navigate cells to ferroptosis. Nat. Chem. Biol. 13, 81-90. doi: 10.1038/nchembio.2238

Kang, Y., Tiziani, S., Park, G., Kaul, M., and Paternostro, G. (2014). Cellular protection using Flt3 and PI3Kalpha inhibitors demonstrates multiple mechanisms of oxidative glutamate toxicity. Nat. Commun. 5:3672. doi: $10.1038 /$ ncomms4672

Kerr, J. F., Wyllie, A. H., and Currie, A. R. (1972). Apoptosis: a basic biological phenomenon with wide-ranging implications in tissue kinetics. Br. J. Cancer 26, 239-257. doi: 10.1038/bjc.1972.33

Kim, H., Choi, J., Ryu, J., Park, S. G., Cho, S., Park, B. C., et al. (2009). Activation of autophagy during glutamate-induced HT22 cell death. Biochem. Biophys. Res. Commun. 388, 339-344. doi: 10.1016/j.bbrc.2009.08.007

Kobayashi, S., Lee, J., Takao, T., and Fujii, J. (2017). Increased ophthalmic acid production is supported by amino acid catabolism under fasting conditions in mice. Biochem. Biophys. Res. Commun. 491, 649-655. doi: 10.1016/j.bbrc.2017.07.149

Kobayashi, S., Sato, M., Kasakoshi, T., Tsutsui, T., Sugimoto, M., Osaki, M., et al. (2015). Cystathionine is a novel substrate of cystine/glutamate transporter: implications for immune function. J. Biol. Chem. 290, 8778-8788. doi: 10.1074/jbc.M114.625053

Kubota, C., Torii, S., Hou, N., Saito, N., Yoshimoto, Y., Imai, H., et al. (2010). Constitutive reactive oxygen species generation from autophagosome/lysosome in neuronal oxidative toxicity. J. Biol. Chem. 285, 667-674. doi: 10.1074/jbc.M109.053058

Kumari, S., Mehta, S. L., and Li, P. A. (2012). Glutamate induces mitochondrial dynamic imbalance and autophagy activation: preventive effects of selenium. PLoS ONE 7:e39382. doi: 10.1371/journal.pone.0039382

Kwan, J. Y., Jeong, S. Y., Van Gelderen, P., Deng, H. X., Quezado, M. M., Danielian, L. E., et al. (2012). Iron accumulation in deep cortical layers accounts for MRI signal abnormalities in ALS: correlating 7 tesla MRI and pathology. PLoS ONE 7:e35241. doi: 10.1371/journal.pone.0035241

Landshamer, S., Hoehn, M., Barth, N., Duvezin-Caubet, S., Schwake, G., Tobaben, S., et al. (2008). Bid-induced release of AIF from mitochondria causes immediate neuronal cell death. Cell Death Differ. 15, 1553-1563. doi: $10.1038 / \mathrm{cdd} .2008 .78$

Lange, P. S., Chavez, J. C., Pinto, J. T., Coppola, G., Sun, C. W., Townes, T. M., et al. (2008). ATF4 is an oxidative stress-inducible, prodeath transcription factor in neurons in vitro and in vivo. J. Exp. Med. 205, 1227-1242. doi: $10.1084 /$ jem.20071460

Laster, S. M., Wood, J. G., and Gooding, L. R. (1988). Tumor necrosis factor can induce both apoptic and necrotic forms of cell lysis. J. Immunol. 141, 2629-2634.

Lee, J. H., Cheon, Y. H., Woo, R. S., Song, D. Y., Moon, C., and Baik, T. K. (2012). Evidence of early involvement of apoptosis inducing factorinduced neuronal death in Alzheimer brain. Anat. Cell Biol. 45, 26-37. doi: $10.5115 /$ acb.2012.45.1.26

Lee, J. K., Shin, J. H., Gwag, B. J., and Choi, E. J. (2015). Iron accumulation promotes TACE-mediated TNF-alpha secretion and neurodegeneration in a mouse model of ALS. Neurobiol. Dis. 80, 63-69. doi: 10.1016/j.nbd.2015.05.009

Lewerenz, J., Baxter, P., Kassubek, R., Albrecht, P., Van Liefferinge, J., Westhoff, M. A., et al. (2014). Phosphoinositide 3-kinases upregulate system xc(-) via eukaryotic initiation factor 2alpha and activating transcription factor 4 - A 
pathway active in glioblastomas and epilepsy. Antioxid. Redox Signal. 20, 2907-2922. doi: 10.1089/ars.2013.5455

Lewerenz, J., Hewett, S. J., Huang, Y., Lambros, M., Gout, P. W., Kalivas, P. W., et al. (2013). The cystine/glutamate antiporter system $\mathrm{x}(\mathrm{c})(-)$ in health and disease: from molecular mechanisms to novel therapeutic opportunities. Antioxid. Redox Signal. 18, 522-555. doi: 10.1089/ars. 2011.4391

Lewerenz, J., Klein, M., and Methner, A. (2006). Cooperative action of glutamate transporters and cystine/glutamate antiporter system Xcprotects from oxidative glutamate toxicity. J. Neurochem. 98, 916-925. doi: 10.1111/j.1471-4159.2006.03921.x

Lewerenz, J., Letz, J., and Methner, A. (2003). Activation of stimulatory heterotrimeric G proteins increases glutathione and protects neuronal cells against oxidative stress. J. Neurochem. 87, 522-531. doi: 10.1046/j.1471-4159.2003.02019.x

Lewerenz, J., and Maher, P. (2009). Basal levels of eIF2alpha phosphorylation determine cellular antioxidant status by regulating ATF4 and xCT expression. J. Biol. Chem. 284, 1106-1115. doi: 10.1074/jbc.M807325200

Lewerenz, J., Sato, H., Albrecht, P., Henke, N., Noack, R., Methner, A., et al. (2012). Mutation of ATF4 mediates resistance of neuronal cell lines against oxidative stress by inducing xCT expression. Cell Death Differ. 19, 847-858. doi: $10.1038 /$ cdd.2011.165

Li, B., and Pratt, D. A. (2015). Methods for determining the efficacy of radical-trapping antioxidants. Free Radic. Biol. Med. 82, 187-202. doi: 10.1016/j.freeradbiomed.2015.01.020

Li, M., Ona, V. O., Guegan, C., Chen, M., Jackson-Lewis, V., Andrews, L. J., et al. (2000). Functional role of caspase-1 and caspase- 3 in an ALS transgenic mouse model. Science 288, 335-339. doi: 10.1126/science.288.5464.335

Li, Q., Han, X., Lan, X., Gao, Y., Wan, J., Durham, F., et al. (2017). Inhibition of neuronal ferroptosis protects hemorrhagic brain. JCI Insight 2:e90777. doi: $10.1172 /$ jci.insight. 90777

Li, Y., Maher, P., and Schubert, D. (1997a). Requirement for cGMP in nerve cell death caused by glutathione depletion. J. Cell Biol. 139, 1317-1324.

Li, Y., Maher, P., and Schubert, D. (1997b). A role for 12-lipoxygenase in nerve cell death caused by glutathione depletion. Neuron 19, 453-463.

Li, Y., Maher, P., and Schubert, D. (1998). Phosphatidylcholine-specific phospholipase C regulates glutamate-induced nerve cell death. Proc. Natl. Acad. Sci. USA. 95, 7748-7753. doi: 10.1073/pnas.95.13.7748

Liu, X., Zou, H., Slaughter, C., and Wang, X. (1997). DFF, a heterodimeric protein that functions downstream of caspase- 3 to trigger DNA fragmentation during apoptosis. Cell 89, 175-184. doi: 10.1016/S0092-8674(00)80197-X

Liu, Y., and Schubert, D. R. (2009). The specificity of neuroprotection by antioxidants. J. Biomed. Sci. 16:98. doi: 10.1186/1423-0127-16-98

Liu, Y., Wang, W., Li, Y., Xiao, Y., Cheng, J., and Jia, J. (2015). The 5lipoxygenase inhibitor zileuton confers neuroprotection against glutamate oxidative damage by inhibiting ferroptosis. Biol. Pharm. Bull. 38, 1234-1239. doi: 10.1248/bpb.b15-00048

Luthi, A. U., and Martin, S. J. (2007). The CASBAH: a searchable database of caspase substrates. Cell Death Differ. 14, 641-650. doi: 10.1038/sj.cdd.4402103

Maher, P. (2001). How protein kinase C activation protects nerve cells from oxidative stress-induced cell death. J. Neurosci. 21, 2929-2938. doi: 10.1523/JNEUROSCI.21-09-02929.2001

Maher, P. (2017). Potentiation of glutathione loss and nerve cell death by the transition metals iron and copper: implications for agerelated neurodegenerative diseases. Free Radic. Biol. Med. 115, 92-104. doi: 10.1016/j.freeradbiomed.2017.11.015

Maher, P., and Davis, J. B. (1996). The role of monoamine metabolism in oxidative glutamate toxicity. J. Neurosci. 16, 6394-6401.

Maher, P., van Leyen, K., Dey, P. N., Honrath, B., Dolga, A., and Methner, A. (2017). The role of $\mathrm{Ca} 2+$ in cell death caused by oxidative glutamate toxicity and ferroptosis. Cell Calcium 70, 47-55. doi: 10.1016/j.ceca.2017.05.007

Malejko, K., Weydt, P., Sussmuth, S. D., Gron, G., Landwehrmeyer, B. G., and Abler, B. (2014). Prodromal Huntington disease as a model for functional compensation of early neurodegeneration. PLOS ONE 9:e114569. doi: 10.1371/journal.pone.0114569

Mandal, P. K., Seiler, A., Perisic, T., Kolle, P., Banjac Canak, A., Forster, H., et al. (2010). System $x(c)$ - and thioredoxin reductase 1 cooperatively rescue glutathione deficiency. J. Biol. Chem. 285, 22244-22253. doi: 10.1074/jbc.M110.121327

Marchetti, P., Susin, S. A., Decaudin, D., Gamen, S., Castedo, M., Hirsch, T., et al. (1996). Apoptosis-associated derangement of mitochondrial function in cells lacking mitochondrial DNA. Cancer Res. 56, 2033-2038.

Martin, L. J., Al-Abdulla, N. A., Brambrink, A. M., Kirsch, J. R., Sieber, F. E., and Portera-Cailliau, C. (1998). Neurodegeneration in excitotoxicity, global cerebral ischemia, and target deprivation: a perspective on the contributions of apoptosis and necrosis. Brain Res. Bull. 46, 281-309. doi: 10.1016/S0361-9230(98)00024-0

Martin, L. J., Liu, Z., Chen, K., Price, A. C., Pan, Y., Swaby, J. A., et al. (2007), Motor neuron degeneration in amyotrophic lateral sclerosis mutant superoxide dismutase-1 transgenic mice: mechanisms of mitochondriopathy and cell death. J. Comp. Neurol. 500, 20-46. doi: 10.1002/cne.21160

McCarthy, N. J., and Evan, G. I. (1998). Methods for detecting and quantifying apoptosis. Curr. Top. Dev. Biol. 36, 259-278. doi: 10.1016/S0070-2153(08)60507-4

Mi, H., Muruganujan, A., and Thomas, P. D. (2013). PANTHER in 2013: modeling the evolution of gene function, and other gene attributes, in the context of phylogenetic trees. Nucleic Acids Res. 41, D377-D386. doi: 10.1093/nar/gks1118

Miyamoto, M., Murphy, T. H., Schnaar, R. L., and Coyle, J. T. (1989). Antioxidants protect against glutamate-induced cytotoxicity in a neuronal cell line. $J$. Pharmacol. Exp. Ther. 250, 1132-1140.

Morimoto, B. H., and Koshland, D. E. Jr. (1991). Identification of cyclic AMP as the response regulator for neurosecretory potentiation: a memory model system. Proc. Natl. Acad. Sci. U.S.A. 88, 10835-10839. doi: 10.1073/pnas.88.23.10835

Mungrue, I. N., Pagnon, J., Kohannim, O., Gargalovic, P. S., and Lusis, A. J. (2009). CHAC1/MGC4504 is a novel proapoptotic component of the unfolded protein response, downstream of the ATF4-ATF3-CHOP cascade. J. Immunol. 182, 466-476. doi: 10.4049/jimmunol.182.1.466

Murphy, T. H., Malouf, A. T., Sastre, A., Schnaar, R. L., and Coyle, J. T. (1988). Calcium-dependent glutamate cytotoxicity in a neuronal cell line. Brain Res. 444, 325-332. doi: 10.1016/0006-8993(88)90941-9

Murphy, T. H., Miyamoto, M., Sastre, A., Schnaar, R. L., and Coyle, J. T. (1989). Glutamate toxicity in a neuronal cell line involves inhibition of cystine transport leading to oxidative stress. Neuron 2, 1547-1558. doi: 10.1016/0896-6273(89)90043-3

Murphy, T. H., Schnaar, R. L., and Coyle, J. T. (1990). Immature cortical neurons are uniquely sensitive to glutamate toxicity by inhibition of cystine uptake. FASEB J. 4, 1624-1633. doi: 10.1096/fasebj.4.6.2180770

Nagamori, S., Wiriyasermkul, P., Guarch, M. E., Okuyama, H., Nakagomi, S., Tadagaki, K., et al. (2016). Novel cystine transporter in renal proximal tubule identified as a missing partner of cystinuria-related plasma membrane protein rBAT/SLC3A1. Proc. Natl. Acad. Sci. U.S.A. 113, 775-780. doi: 10.1073/pnas.1519959113

Nakayama, M., Uchimura, K., Zhu, R. L., Nagayama, T., Rose, M. E., Stetler, R. A., et al. (1998). Cyclooxygenase-2 inhibition prevents delayed death of CA1 hippocampal neurons following global ischemia. Proc. Natl. Acad. Sci. U.S.A. 95, 10954-10959. doi: 10.1073/pnas.95.18.10954

Neitemeier, S., Jelinek, A., Laino, V., Hoffmann, L., Eisenbach, I., Eying, R., et al. (2017). BID links ferroptosis to mitochondrial cell death pathways. Redox Biol. 12, 558-570. doi: 10.1016/j.redox.2017.03.007

Noack, R., Frede, S., Albrecht, P., Henke, N., Pfeiffer, A., Knoll, K., et al. (2012). Charcot-Marie-Tooth disease CMT4A: GDAP1 increases cellular glutathione and the mitochondrial membrane potential. Hum. Mol. Genet. 21, 150-162. doi: $10.1093 / \mathrm{hmg} / \mathrm{ddr} 450$

Norberg, E., Gogvadze, V., Ott, M., Horn, M., Uhlen, P., Orrenius, S., et al. (2008). An increase in intracellular $\mathrm{Ca} 2+$ is required for the activation of mitochondrial calpain to release AIF during cell death. Cell Death Differ. 15, 1857-1864. doi: 10.1038/cdd.2008.123

Oh, J., An, J. W., Oh, S. I., Oh, K. W., Kim, J. A., Lee, J. S., et al. (2015). Socioeconomic costs of amyotrophic lateral sclerosis according to staging system. Amyotroph. Lateral Scler. Frontotemporal Degener. 16, 202-208. doi: 10.3109/21678421.2014.999791

Oh, Y. K., Shin, K. S., and Kang, S. J. (2006). AIF translocates to the nucleus in the spinal motor neurons in a mouse model of ALS. Neurosci. Lett. 406, 205-210. doi: 10.1016/j.neulet.2006.07.044 
Ong, Q., Guo, S., Zhang, K., and Cui, B. (2015). U0126 protects cells against oxidative stress independent of its function as a MEK inhibitor. ACS Chem. Neurosci. 6, 130-137. doi: 10.1021/cn500288n

Ou, Y., Wang, S. J., Li, D., Chu, B., and Gu, W. (2016). Activation of SAT1 engages polyamine metabolism with p53-mediated ferroptotic responses. Proc. Natl. Acad. Sci. U.S.A. 113, E6806-E6812. doi: 10.1073/pnas.1607152113

Pallast, S., Arai, K., Wang, X., Lo, E. H., and van Leyen, K. (2009). 12/15-Lipoxygenase targets neuronal mitochondria under oxidative stress. J. Neurochem. 111, 882-889. doi: 10.1111/j.1471-4159.2009.06379.x

Park, U. J., Lee, Y. A., Won, S. M., Lee, J. H., Kang, S. H., Springer, J. E., et al. (2011). Blood-derived iron mediates free radical production and neuronal death in the hippocampal CA1 area following transient forebrain ischemia in rat. Acta Neuropathol. 121, 459-473. doi: 10.1007/s00401-010-0785-8

Penney, J. B. Jr., Vonsattel, J. P., MacDonald, M. E., Gusella, J. F., and Myers, R. H. (1997). CAG repeat number governs the development rate of pathology in Huntington's disease. Ann. Neurol. 41, 689-692. doi: 10.1002/ana.410410521

Perez Velazquez, J. L., Kokarovtseva, L., Sarbaziha, R., Jeyapalan, Z., and Leshchenko, Y. (2006). Role of gap junctional coupling in astrocytic networks in the determination of global ischaemia-induced oxidative stress and hippocampal damage. Eur. J. Neurosci. 23, 1-10. doi: 10.1111/j.1460-9568.2005.04523.x

Pfeiffer, A., Jaeckel, M., Lewerenz, J., Noack, R., Pouya, A., Schacht, T., et al. (2013). Mitochondrial function and energy metabolism in neuronal HT22 cells resistant to oxidative stress. Br. J. Pharmacol. 171, 2147-2158. doi: $10.1111 /$ bph. 12549

Pfeiffer, A., Schneider, J., Bueno, D., Dolga, A., Voss, T. D., Lewerenz, J., et al. (2017). Bcl-xL knockout attenuates mitochondrial respiration and causes oxidative stress that is compensated by pentose phosphate pathway activity. Free Radic. Biol. Med. 112, 350-359. doi: 10.1016/j.freeradbiomed.2017.08.007

Portera-Cailliau, C., Hedreen, J. C., Price, D. L., and Koliatsos, V. E. (1995). Evidence for apoptotic cell death in Huntington disease and excitotoxic animal models. J. Neurosci. 15, 3775-3787.

Probst, L., Dachert, J., Schenk, B., and Fulda, S. (2017). Lipoxygenase inhibitors protect acute lymphoblastic leukemia cells from ferroptotic cell death. Biochem. Pharmacol. 140, 41-52. doi: 10.1016/j.bcp.2017.06.112

Pyatigorskaya, N., Sharman, M., Corvol, J. C., Valabregue, R., Yahia-Cherif, L., Poupon, F., et al. (2015). High nigral iron deposition in LRRK2 and Parkin mutation carriers using R2* relaxometry. Mov. Disord. 30, 1077-1084. doi: $10.1002 / \mathrm{mds} .26218$

Ratan, R. R., Murphy, T. H., and Baraban, J. M. (1994). Macromolecular synthesis inhibitors prevent oxidative stress-induced apoptosis in embryonic cortical neurons by shunting cysteine from protein synthesis to glutathione. J. Neurosci. $14,4385-4392$

Re, D. B., Le Verche, V., Yu, C., Amoroso, M. W., Politi, K. A., Phani, S., et al. (2014). Necroptosis drives motor neuron death in models of both sporadic and familial ALS. Neuron 81, 1001-1008. doi: 10.1016/j.neuron.2014.01.011

Robine, J. M., and Cubaynes, S. (2017). Worldwide demography of centenarians. Mech. Ageing Dev. 165, 59-67. doi: 10.1016/j.mad.2017.03.004

Rosemary Siafakas, A., and Richardson, D. R. (2009). Growth arrest and DNA damage-45 alpha (GADD45alpha). Int. J. Biochem. Cell Biol. 41, 986-989. doi: 10.1016/j.biocel.2008.06.018

Sagara, Y., Dargusch, R., Chambers, D., Davis, J., Schubert, D., and Maher, P. (1998). Cellular mechanisms of resistance to chronic oxidative stress. Free Radic. Biol. Med. 24, 1375-1389. doi: 10.1016/S0891-5849(97)00457-7

Sahin, M., Saxena, A., Joost, P., Lewerenz, J., and Methner, A. (2006). Induction of Bcl-2 by functional regulation of G-protein coupled receptors protects from oxidative glutamate toxicity by increasing glutathione. Free Radic. Res. 40, 1113-1123. doi: 10.1080/10715760600838191

Sato, H., Shiiya, A., Kimata, M., Maebara, K., Tamba, M., Sakakura, Y., et al. (2005). Redox imbalance in cystine/glutamate transporter-deficient mice. J. Biol. Chem. 280, 37423-37429. doi: 10.1074/jbc.M506439200

Satoh, T., Nakatsuka, D., Watanabe, Y., Nagata, I., Kikuchi, H., and Namura, S. (2000). Neuroprotection by MAPK/ERK kinase inhibition with U0126 against oxidative stress in a mouse neuronal cell line and rat primary cultured cortical neurons. Neurosci. Lett. 288, 163-166. doi: 10.1016/S0304-3940(00)01229-5

Schmidt-Kastner, R. (2015). Genomic approach to selective vulnerability of the hippocampus in brain ischemia-hypoxia. Neuroscience 309, 259-279. doi: 10.1016/j.neuroscience.2015.08.034
Schriever, S. C., Zimprich, A., Pfuhlmann, K., Baumann, P., Giesert, F., Klaus, V., et al. (2017). Alterations in neuronal control of body weight and anxiety behavior by glutathione peroxidase 4 deficiency. Neuroscience 357, 241-254. doi: 10.1016/j.neuroscience.2017.05.050

Schubert, D., and Piasecki, D. (2001). Oxidative glutamate toxicity can be a component of the excitotoxicity cascade. J. Neurosci. 21, 7455-7462.

Schubert, D., Kimura, H., and Maher, P. (1992). Growth factors and vitamin E modify neuronal glutamate toxicity. Proc. Natl. Acad. Sci. U.S.A. 89, 8264-8267. doi: $10.1073 /$ pnas.89.17.8264

Seiler, A., Schneider, M., Forster, H., Roth, S., Wirth, E. K., Culmsee, C., et al. (2008). Glutathione peroxidase 4 senses and translates oxidative stress into 12/15-lipoxygenase dependent- and AIF-mediated cell death. Cell Metab. 8, 237-248. doi: 10.1016/j.cmet.2008.07.005

Selvakumaran, M., Lin, H. K., Miyashita, T., Wang, H. G., Krajewski, S., Reed, J. C., et al. (1994). Immediate early up-regulation of bax expression by p53 but not TGF beta 1: a paradigm for distinct apoptotic pathways. Oncogene 9 , 1791-1798.

Sen, S., Kawahara, B., and Chaudhuri, G. (2012). Maintenance of higher $\mathrm{H}(2) \mathrm{O}(2)$ levels, and its mechanism of action to induce growth in breast cancer cells: important roles of bioactive catalase and PP2A. Free Radic. Biol. Med. 53, 1541-1551. doi: 10.1016/j.freeradbiomed.2012.06.030

Sengupta, A., Lichti, U. F., Carlson, B. A., Cataisson, C., Ryscavage, A. O., Mikulec, C., et al. (2013). Targeted disruption of glutathione peroxidase 4 in mouse skin epithelial cells impairs postnatal hair follicle morphogenesis that is partially rescued through inhibition of COX-2. J. Invest. Dermatol. 133, 1731-1741. doi: 10.1038/jid.2013.52

Shchepinov, M. S., Chou, V. P., Pollock, E., Langston, J. W., Cantor, C. R., Molinari, R. J., et al. (2011). Isotopic reinforcement of essential polyunsaturated fatty acids diminishes nigrostriatal degeneration in a mouse model of Parkinson's disease. Toxicol. Lett. 207, 97-103. doi: 10.1016/j.toxlet.2011.07.020

Shibata, N., Kakita, A., Takahashi, H., Ihara, Y., Nobukuni, K., Fujimura, H., et al. (2009). Persistent cleavage and nuclear translocation of apoptosisinducing factor in motor neurons in the spinal cord of sporadic amyotrophic lateral sclerosis patients. Acta Neuropathol. 118, 755-762. doi: 10.1007/s00401-009-0580-6

Shibata, S., Furuta, K., Oh-Hashi, K., Ueda, H., Kiuchi, K., and Hirata, Y. (2017). Prevention of oxytosis-induced c-Raf down-regulation by (arylthio)cyclopentenone prostaglandins is neuroprotective. Toxicology 390, 83-87. doi: 10.1016/j.tox.2017.09.006

Shigeno, T., Yamasaki, Y., Kato, G., Kusaka, K., Mima, T., Takakura, K., et al. (1990). Reduction of delayed neuronal death by inhibition of protein synthesis. Neurosci. Lett. 120, 117-119. doi: 10.1016/0304-3940(90)90182-9

Shih, A. Y., Erb, H., Sun, X., Toda, S., Kalivas, P. W., and Murphy, T. H. (2006). Cystine/glutamate exchange modulates glutathione supply for neuroprotection from oxidative stress and cell proliferation. J. Neurosci. 26, 10514-10523. doi: 10.1523/JNEUROSCI.3178-06.2006

Shivakumar, B. R., Kolluri, S. V., and Ravindranath, V. (1995). Glutathione and protein thiol homeostasis in brain during reperfusion after cerebral ischemia. $J$. Pharmacol. Exp. Ther. 274, 1167-1173.

Sian, J., Dexter, D. T., Lees, A. J., Daniel, S., Agid, Y., Javoy-Agid, F., et al. (1994). Alterations in glutathione levels in Parkinson's disease and other neurodegenerative disorders affecting basal ganglia. Ann. Neurol. 36, 348-355. doi: 10.1002/ana.410360305

Skouta, R., Dixon, S. J., Wang, J., Dunn, D. E., Orman, M., Shimada, K., et al. (2014). Ferrostatins inhibit oxidative lipid damage and cell death in diverse disease models. J. Am. Chem. Soc. 136, 4551-4556. doi: 10.1021/ja411006a

Smulson, M. E., Simbulan-Rosenthal, C. M., Boulares, A. H., Yakovlev, A., Stoica, B., Iyer, S., et al. (2000). Roles of poly(ADP-ribosyl)ation and PARP in apoptosis, DNA repair, genomic stability and functions of p53 and E2F-1. Adv. Enzyme Regul. 40, 183-215. doi: 10.1016/S0065-2571(99) $00024-2$

Sorrells, S. F., Paredes, M. F., Cebrian-Silla, A., Sandoval, K., Qi, D., Kelley, K.W., et al. (2018). Human hippocampal neurogenesis drops sharply in children to undetectable levels in adults. Nature 555, 377-381. doi: 10.1038/nature25975

Soucek, T., Cumming, R., Dargusch, R., Maher, P., and Schubert, D. (2003). The regulation of glucose metabolism by HIF-1 mediates a neuroprotective response to amyloid beta peptide. Neuron 39, 43-56. doi: $10.1016 /$ S0896-6273(03)00367-2 
Stack, E. C., Matson, W. R., and Ferrante, R. J. (2008). Evidence of oxidant damage in Huntington's disease: translational strategies using antioxidants. Ann. N. Y. Acad. Sci. 1147, 79-92. doi: 10.1196/annals.1427.008

Stanciu, M., Wang, Y., Kentor, R., Burke, N., Watkins, S., Kress, G., et al. (2000). Persistent activation of ERK contributes to glutamate-induced oxidative toxicity in a neuronal cell line and primary cortical neuron cultures. J. Biol. Chem. 275, 12200-12206. doi: 10.1074/jbc.275.16.12200

Sun, L., Wang, H., Wang, Z., He, S., Chen, S., Liao, D., et al. (2012). Mixed lineage kinase domain-like protein mediates necrosis signaling downstream of RIP3 kinase. Cell 148, 213-227. doi: 10.1016/j.cell.2011.11.031

Susin, S. A., Lorenzo, H. K., Zamzami, N., Marzo, I., Snow, B. E., Brothers, G. M., et al. (1999). Molecular characterization of mitochondrial apoptosis-inducing factor. Nature 397, 441-446. doi: 10.1038/17135

Susin, S. A., Zamzami, N., Castedo, M., Hirsch, T., Marchetti, P., Macho, A., et al. (1996). Bcl-2 inhibits the mitochondrial release of an apoptogenic protease. J. Exp. Med. 184, 1331-1341. doi: 10.1084/jem.184.4.1331

Tan, S., Sagara, Y., Liu, Y., Maher, P., and Schubert, D. (1998a). The regulation of reactive oxygen species production during programmed cell death. J. Cell Biol. 141, 1423-1432.

Tan, S., Schubert, D., and Maher, P. (2001a). Oxytosis: a novel form of programmed cell death. Curr. Top. Med. Chem. 1, 497-506. doi: 10.2174/1568026013394741

Tan, S., Somia, N., Maher, P., and Schubert, D. (2001b). Regulation of antioxidant metabolism by translation initiation factor $2 \alpha$. J. Cell Biol. 152, 997-1006. doi: $10.1083 /$ jcb.152.5.997

Tan, S., Wood, M., and Maher, P. (1998b). Oxidative stress induces a form of programmed cell death with characteristics of both apoptosis and necrosis in neuronal cells. J. Neurochem. 71, 95-105.

Thomas, C. E., Morehouse, L. A., and Aust, S. D. (1985). Ferritin and superoxidedependent lipid peroxidation. J. Biol. Chem. 260, 3275-3280.

Tirosh, O., Sen, C. K., Roy, S., and Packer, L. (2000). Cellular and mitochondrial changes in glutamate-induced HT4 neuronal cell death. Neuroscience 97, 531-541. doi: 10.1016/S0306-4522(00)00028-2

Torii, S., Shintoku, R., Kubota, C., Yaegashi, M., Torii, R., Sasaki, M., et al. (2016). An essential role for functional lysosomes in ferroptosis of cancer cells. Biochem. J. 473, 769-777. doi: 10.1042/BJ20150658

Toutzaris, D., Lewerenz, J., Albrecht, P., Jensen, L. T., Letz, J., Geerts, A., et al. (2010). A novel giant peroxisomal superoxide dismutase motif-containing protein. Free Radic. Biol. Med. 48, 811-820. doi: 10.1016/j.freeradbiomed.2009.12.023

Tsuji, Y., Ayaki, H., Whitman, S. P., Morrow, C. S., Torti, S. V., and Torti, F. M. (2000). Coordinate transcriptional and translational regulation of ferritin in response to oxidative stress. Mol. Cell. Biol. 20, 5818-5827. doi: 10.1128/MCB.20.16.5818-5827.2000

$\mathrm{Tu}$, B. P., and Weissman, J. S. (2004). Oxidative protein folding in eukaryotes: mechanisms and consequences. J. Cell Biol. 164, 341-346. doi: $10.1083 /$ jcb.200311055

Tuo, Q. Z., Lei, P., Jackman, K. A., Li, X. L., Xiong, H., Li, X. L., et al. (2017). Taumediated iron export prevents ferroptotic damage after ischemic stroke. Mol. Psychiatry 22, 1520-1530. doi: 10.1038/mp.2017.171

Turmaine, M., Raza, A., Mahal, A., Mangiarini, L., Bates, G. P., and Davies, S. W. (2000). Nonapoptotic neurodegeneration in a transgenic mouse model of Huntington's disease. Proc. Natl. Acad. Sci. U.S.A. 97, 8093-8097. doi: 10.1073/pnas.110078997

Ursini, F., Maiorino, M., Valente, M., Ferri, L., and Gregolin, C. (1982). Purification from pig liver of a protein which protects liposomes and biomembranes from peroxidative degradation and exhibits glutathione peroxidase activity on phosphatidylcholine hydroperoxides. Biochim. Biophys. Acta 710, 197-211. doi: 10.1016/0005-2760(82)90150-3

Vanden Berghe, T., Hassannia, B., and Vandenabeele, P. (2016). An outline of necrosome triggers. Cell. Mol. Life Sci. 73, 2137-2152. doi: 10.1007/s00018-016-2189-y

van Leyen, K., Duvoisin, R. M., Engelhardt, H., and Wiedmann, M. (1998). A function for lipoxygenase in programmed organelle degradation. Nature 395, 392-395. doi: 10.1038/26500

van Rooden, S., Doan, N. T., Versluis, M. J., Goos, J. D., Webb, A. G., Oleksik, A. M., et al. (2015). $7 \mathrm{~T} \mathrm{~T}(2)^{*}$-weighted magnetic resonance imaging reveals cortical phase differences between early- and late-onset Alzheimer's disease. Neurobiol. Aging 36, 20-26. doi: 10.1016/j.neurobiolaging.2014.07.006
Vercammen, D., Beyaert, R., Denecker, G., Goossens, V., Van Loo, G., Declercq, W., et al. (1998a). Inhibition of caspases increases the sensitivity of L929 cells to necrosis mediated by tumor necrosis factor. J. Exp. Med. 187, 1477-1485.

Vercammen, D., Brouckaert, G., Denecker, G., Van de Craen, M., Declercq, W., Fiers, W., et al. (1998b). Dual signaling of the Fas receptor: initiation of both apoptotic and necrotic cell death pathways. J. Exp. Med. 188, 919-930.

Verity, N. C., and Mallucci, G. R. (2011). Rescuing neurons in prion disease. Biochem. J. 433, 19-29. doi: 10.1042/BJ20101323

Vis, J. C., Schipper, E., de Boer-van Huizen, R. T., Verbeek, M. M., de Waal, R. M., Wesseling, P., et al. (2005). Expression pattern of apoptosisrelated markers in Huntington's disease. Acta Neuropathol. 109, 321-328. doi: 10.1007/s00401-004-0957-5

Wang, H., Sun, L., Su, L., Rizo, J., Liu, L., Wang, L. F., et al. (2014). Mixed lineage kinase domain-like protein MLKL causes necrotic membrane disruption upon phosphorylation by RIP3. Mol. Cell 54, 133-146. doi: 10.1016/j.molcel.2014.03.003

Wek, R. C., Jiang, H. Y., and Anthony, T. G. (2006). Coping with stress: eIF2 kinases and translational control. Biochem. Soc. Trans. 34, 7-11. doi: $10.1042 /$ BST0340007

Wenzel, S. E., Tyurina, Y. Y., Zhao, J., St Croix, C. M., Dar, H. H., Mao, G., et al. (2017). PEBP1 Wardens Ferroptosis by Enabling Lipoxygenase Generation of Lipid Death Signals. Cell 171, 628.e26-641.e26. doi: 10.1016/j.cell.2017.09.044

Wolpaw, A. J., Shimada, K., Skouta, R., Welsch, M. E., Akavia, U. D., Pe'er, D., et al. (2011). Modulatory profiling identifies mechanisms of small molecule-induced cell death. Proc. Natl. Acad. Sci. U.S.A. 108, E771-E780. doi: 10.1073/pnas.1106149108

Wyllie, A. H. (1980). Glucocorticoid-induced thymocyte apoptosis is associated with endogenous endonuclease activation. Nature 284, 555-556. doi: $10.1038 / 284555 \mathrm{a} 0$

Xie, Y., Zhu, S., Song, X., Sun, X., Fan, Y., Liu, J., et al. (2017). The Tumor Suppressor p53 Limits Ferroptosis by Blocking DPP4 Activity. Cell Rep. 20, 1692-1704. doi: 10.1016/j.celrep.2017.07.055

Yagoda, N., von Rechenberg, M., Zaganjor, E., Bauer, A. J., Yang, W. S., Fridman, D. J., et al. (2007). RAS-RAF-MEK-dependent oxidative cell death involving voltage-dependent anion channels. Nature 447, 864-868. doi: 10.1038 /nature05859

Yamada, T., McGeer, P. L., Baimbridge, K. G., and McGeer, E. G. (1990). Relative sparing in Parkinson's disease of substantia nigra dopamine neurons containing calbindin-D28K. Brain Res. 526, 303-307. doi: 10.1016/0006-8993(90) 91236-A

Yang, W. S., Kim, K. J., Gaschler, M. M., Patel, M., Shchepinov, M. S., and Stockwell, B. R. (2016). Peroxidation of polyunsaturated fatty acids by lipoxygenases drives ferroptosis. Proc. Natl. Acad. Sci. U.S.A. 113, E4966E4975. doi: 10.1073/pnas.1603244113

Yang, W. S., SriRamaratnam, R., Welsch, M. E., Shimada, K., Skouta, R., Viswanathan, V. S., et al. (2014). Regulation of ferroptotic cancer cell death by GPX4. Cell 156, 317-331. doi: 10.1016/j.cell.2013.12.010

Yang, W. S., and Stockwell, B. R. (2008). Synthetic lethal screening identifies compounds activating iron-dependent, nonapoptotic cell death in oncogenic-RAS-harboring cancer cells. Chem. Biol. 15, 234-245. doi: 10.1016/j.chembiol.2008.02.010

Yigitkanli, K., Zheng, Y., Pekcec, A., Lo, E. H., and van Leyen, K. (2017). Increased 12/15-lipoxygenase leads to widespread brain injury following global cerebral ischemia. Transl. Stroke Res. 8, 194-202. doi: 10.1007/s12975-016-0509-z

Yoo, S. E., Chen, L., Na, R., Liu, Y., Rios, C., Van Remmen, H., et al. (2012). Gpx4 ablation in adult mice results in a lethal phenotype accompanied by neuronal loss in brain. Free Radic. Biol. Med. 52, 1820-1827. doi: 10.1016/j.freeradbiomed.2012.02.043

Yu, S. W., Wang, H., Poitras, M. F., Coombs, C., Bowers, W. J., Federoff, H. J., et al. (2002). Mediation of poly(ADP-ribose) polymerase-1-dependent cell death by apoptosis-inducing factor. Science 297, 259-263. doi: 10.1126/science.1072221

Yu, W., Mechawar, N., Krantic, S., and Quirion, R. (2010). Evidence for the involvement of apoptosis-inducing factor-mediated caspase-independent neuronal death in Alzheimer disease. Am. J. Pathol. 176, 2209-2218. doi: 10.2353/ajpath.2010.090496

Yuan, H., Li, X., Zhang, X., Kang, R., and Tang, D. (2016). Identification of ACSL4 as a biomarker and contributor of ferroptosis. Biochem. Biophys. Res. Commun. 478, 1338-1343. doi: 10.1016/j.bbrc.2016.08.124 
Zaman, K., Ryu, H., Hall, D., O’Donovan, K., Lin, K. I., Miller, M. P., et al. (1999). Protection from oxidative stress-induced apoptosis in cortical neuronal cultures by iron chelators is associated with enhanced DNA binding of hypoxiainducible factor-1 and ATF-1/CREB and increased expression of glycolytic enzymes, p21(waf1/cip1), and erythropoietin. J. Neurosci. 19, 9821-9830.

Zhan, Q., Bae, I., Kastan, M. B., and Fornace, A. J. Jr. (1994). The p53-dependent gamma-ray response of GADD45. Cancer Res. 54, 2755-2760.

Zhang, M., Song, J. N., Wu, Y., Zhao, Y. L., Pang, H. G., Fu, Z. F., et al. (2014). Suppression of STIM1 in the early stage after global ischemia attenuates the injury of delayed neuronal death by inhibiting store-operated calcium entry-induced apoptosis in rats. Neuroreport 25, 507-513. doi: 10.1097/WNR.0000000000000127

Zhang, Y., and Bhavnani, B. R. (2006). Glutamate-induced apoptosis in neuronal cells is mediated via caspase-dependent and independent mechanisms involving calpain and caspase- 3 proteases as well as apoptosis inducing factor (AIF) and this process is inhibited by equine estrogens. BMC Neurosci. 7:49. doi: $10.1186 / 1471-2202-7-49$
Zilka, O., Shah, R., Li, B., Friedmann Angeli, J. P., Griesser, M., Conrad, M., et al. (2017). On the mechanism of cytoprotection by ferrostatin1 and liproxstatin-1 and the role of lipid peroxidation in ferroptotic cell death. ACS Cent. Sci. 3, 232-243. doi: 10.1021/acscentsci. $7 \mathrm{~b} 00028$

Conflict of Interest Statement: The authors declare that the research was conducted in the absence of any commercial or financial relationships that could be construed as a potential conflict of interest.

Copyright $\odot 2018$ Lewerenz, Ates, Methner, Conrad and Maher. This is an openaccess article distributed under the terms of the Creative Commons Attribution License (CC BY). The use, distribution or reproduction in other forums is permitted, provided the original author(s) and the copyright owner are credited and that the original publication in this journal is cited, in accordance with accepted academic practice. No use, distribution or reproduction is permitted which does not comply with these terms. 